\title{
Three new species of Thelepus Leuckart, 1849 from Europe and a re-description of T. cincinnatus (Fabricius, 1780) (Annelida, Terebellidae)
}

\author{
Igor Jirkov' \\ I Department of Hydrobiology, Biological Faculty, Moscow Lomonosov State University, Moscow, Russia \\ Corresponding author: Igor Jirkov (ampharete@yandex.ru)
}

Academic editor: C. Glasby | Received 13 December 2017 | Accepted 4 April 2018 | Published 17 May 2018

http://zoobank.org/A7645CBD-F29D-4F99-A2C5-709197B95F28

Citation: Jirkov I (2018) Three new species of Thelepus Leuckart, 1849 from Europe and a re-description of T. cincinnatus (Fabricius, 1780) (Annelida, Terebellidae). ZooKeys 759: 29-56. https://doi.org/10.3897/zookeys.759.22981

\begin{abstract}
The review of a large amount of material previously identified as the terebellid annelid, Thelepus cincinnatus (Fabricius, 1780) shows that, within European waters from the Mediterranean to the North Pole, this species should be split into four species, three of which (T. davehalli sp. n., T. marthae sp. n., and T. parapari sp. n.) are newly described here and T. cincinnatus s. str. is re-described. These four species each show distinct distribution ranges. Thelepus cincinnatus has notopodia on almost all segments and numerous eyespots; it inhabits the high boreal and arctic shelf and the North Atlantic slope, and probably also occurs on the North Pacific shelf and slope. Thelepus marthae sp. n. has no eyespots and inhabits deep waters of the high Arctic. Thelepus davehalli sp. n. has no eyespots and has notopodia on 1/2 to 2/3 of the anterior of the body; it inhabits boreal shelf waters (from Iceland to the Mediterranean) below the tidal front. Thelepus parapari sp. $\mathbf{n}$. differs from the previous three species in that the uncini of the first uncinigerous segment has two teeth above the main fang; it inhabits shallow, coastal waters of the Mediterranean, inshore from the tidal front.
\end{abstract}

\section{Keywords}

cosmopolitan species, generic characteristic, identification key, morphological characters, Polychaeta, taxonomic revision, taxonomy

Copyright lgor Jirkov. This is an open access article distributed under the terms of the Creative Commons Attribution License (CC BY 4.0), which permits unrestricted use, distribution, and reproduction in any medium, provided the original author and source are credited. 


\section{Introduction}

Thirty years ago, Hutchings and Glasby stated "Many species of Thelepus have been described, but many inadequately, and type material in most cases needs to be re-examined" (Hutchings and Glasby 1987: 226). Unfortunately, this situation has persisted and led to the appearance of another "cosmopolitan species", which is, in reality, a complex of pseudocryptic species. The type species of Thelepus, T. cincinnatus, was reported as cosmopolitan by Hartmann-Schröder (1996). Despite being absent from the tropics (thus not truly cosmopolitan), its reported range is very wide: from the eastern North Atlantic, from Cape Verde in the south, through the Mediterranean to the western North Atlantic and the Caribbean, the North Polar Basin and the North Pacific: Japan and Washington (Uschakov 1955; Imajima and Hartman 1964; Hobson and Banse 1981; Holthe 1986; Jirkov 2001). Hartman (1966) also reported T. cincinnatus amongst Antarctic polychaetes. Existing records indicate a vertical distribution from the eulittoral zone to a depth of ca. $4000 \mathrm{~m}$ (Holthe 1986). However, recent investigations indicate the species' true range is not as extensive, with the Caribbean for example already excluded from its range (Londoño-Mesa 2009). The extensive range and habitat preferences of T. cincinnatus were investigated during the examination of European material for the Fauna Ibérica Project. As a result, instead of the single species T. cincinnatus, these records indicate four species: T. cincinnatus s. str. and three new species described here. The previously reported range of T. cincinnatus within the Arctic and North Atlantic is thus divided between these four species. It should be noted that T. cincinnatus also has a long list of subjective synonyms: 12 according to Bellan (2008); Fauvel (1927) also accepted T. nucleolata (valid according to Hsueh and $\mathrm{Li} 2016$ ) as a synonym of T. cincinnatus. Unfortunately, all these synonymized taxa were described at least a century ago, and have poor original descriptions and an absence of type material; it is not possible to confirm their taxonomic status.

\section{Materials and methods}

The higher taxonomy used in this paper follows Read and Fauchald (2018). Morphological terms used in this paper follow Nogueira et al. (2010) and are explained in Fig. 1A. Taxonomic abbreviations used are as follows:
BS branchiferous seg-
C chaetiger;
T thoracic; ment;
S segment;
$\mathrm{U}$ unciniger.

The number following the abbreviation refers to the number of the segment (e.g. BS1 means branchiferous segment 1). Institutional abbreviations used are as follows:
APEM APEM Ltd., UK;
Aveiro Biology Department of the Universidade de Aveiro, Portugal;
KGB Department of Hydrobiology Moscow Lomonosov State University, Russia; 


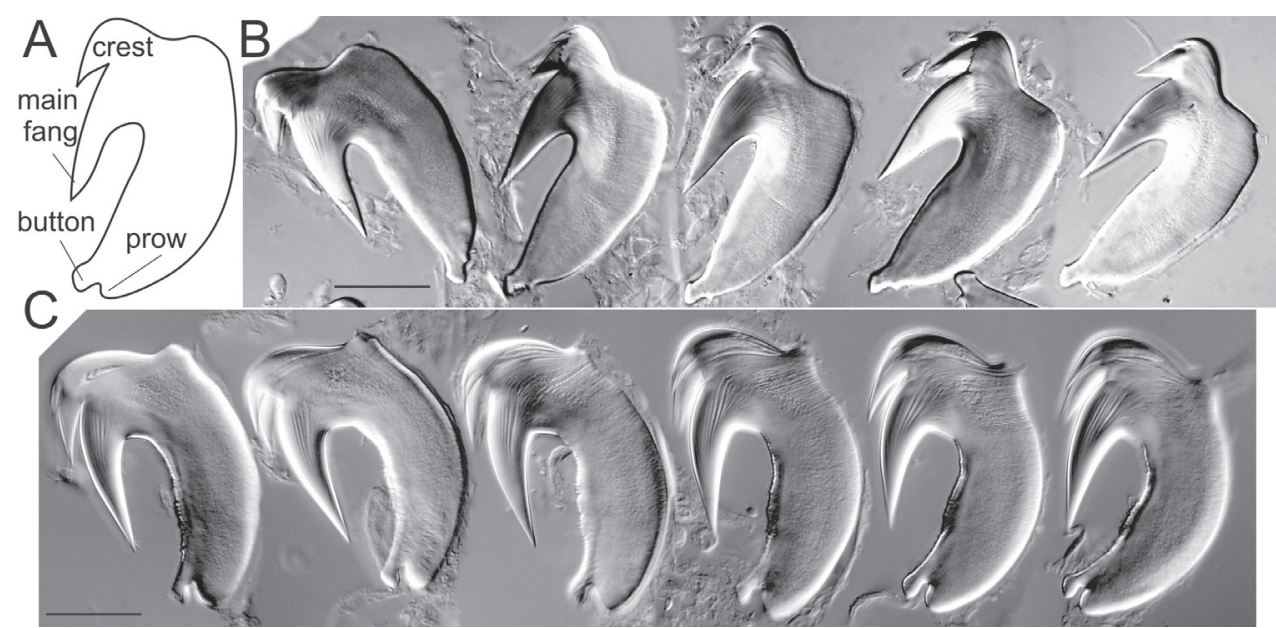

Figure I. Uncinial parts and uncini of T. triserialis and T. setosus. A uncinial parts according to Nogueira et al. (2010) B uncini U1 T. setosus APEM 413169 C uncini U1 T. triserialis MNCN 2508. Scale bars: $20 \mu \mathrm{m}$.

MNCN Museo Nacional de Ciencias Naturales, Madrid, Spain;

ZIN Zoological Institute of Russian Academy of Science, St. Petersburg, Russia.

This study was based almost exclusively on collections from the KGB. Mediterranean specimens were examined from the collection at the $\mathrm{MNCN}$; specimens from UK waters were examined from the APEM collection. All material, if not stated otherwise, is deposited at KGB. Sampling data are given in Table 1.

Photographs were produced at the PP Shirshov Institute of Oceanology, at the Russian Academy of Science, Moscow using a Leica DFC490 camera mounted on either a Leica M165C stereomicroscope or a Leica DMI 4000B compound microscope; at the Department of Invertebrate Zoology, Biological Faculty, Moscow State University using a Leica DFC425C camera mounted on a Leica DMI 5000B compound microscope; and at the MNCN by a Leica DFC550 camera mounted on a Leica MZ16A stereomicroscope. In order to increase contrast, specimens were stained with methylene blue (water solution).

Some external morphological characters are not always and/or easily visible. Eyespots are located on back of upper lip, which is usually curved backward, so it is necessary to unbend the lip forwards to observe this feature (Fig. 2C-F). Additionally, sometimes eyespots do not form an entire band; instead, a dorsally interrupted band is present, so careful examination is required. Nephridial papillae are often poorly visible, so it is necessary to investigate several specimens, preferably well preserved and mature to get a clear picture. Counting the number of branchial filaments requires careful examination as it will appear that more rows are present due to the presence of numerous obscuring filaments. Some characters develop ontogenetically. Unfortunately usually specimens are incomplete, so it is not possible to assess age of specimen using its length. Further, length greatly depends on the degree of retraction 


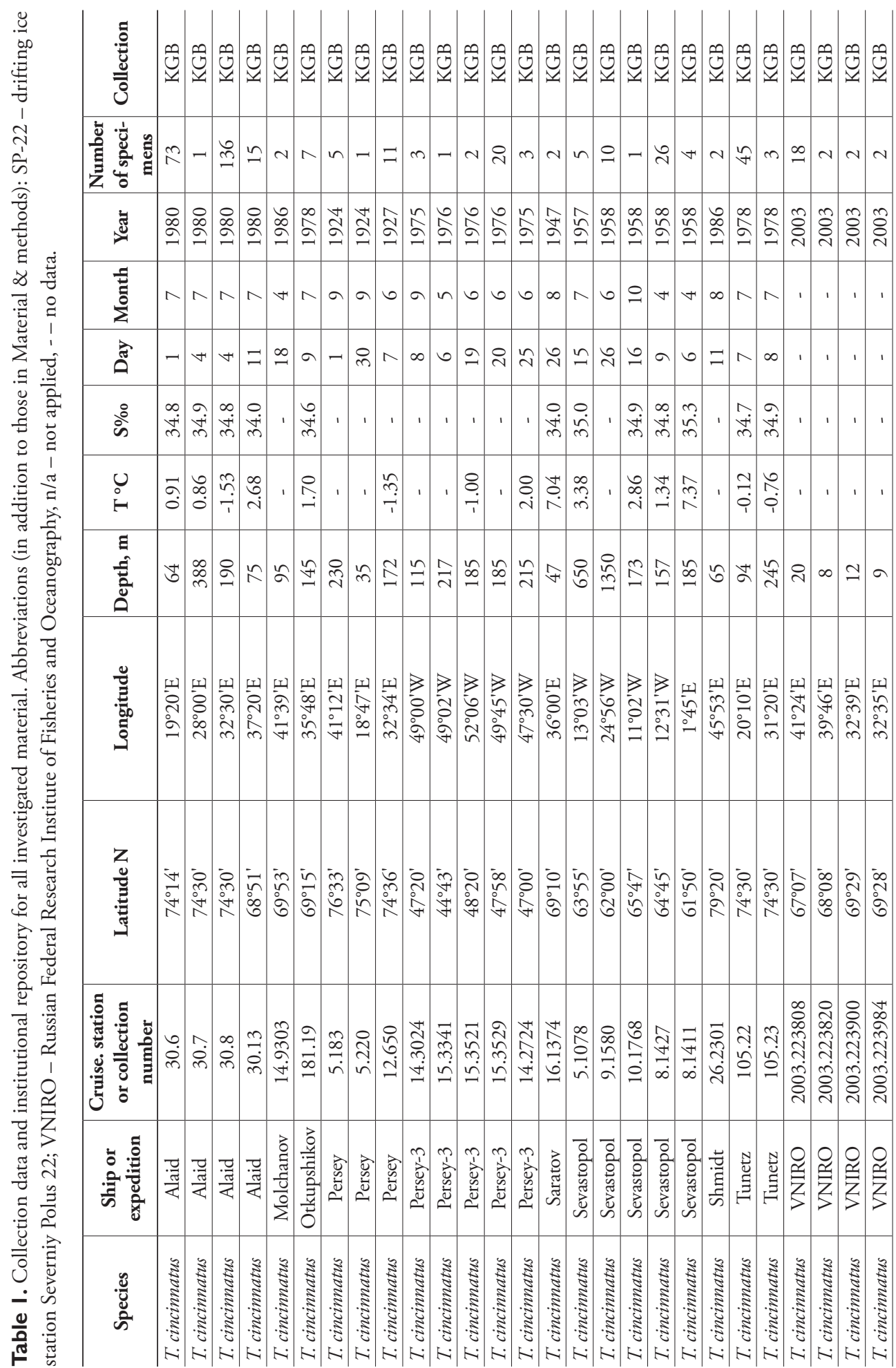




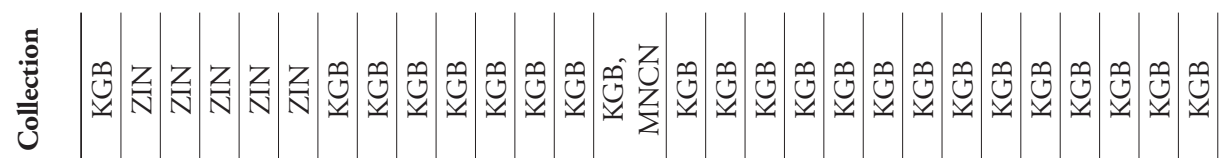

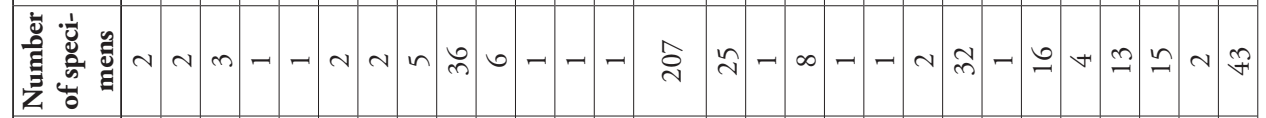

兑

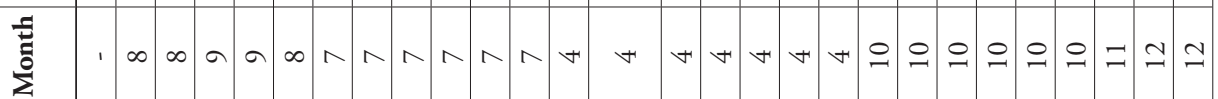

อ.

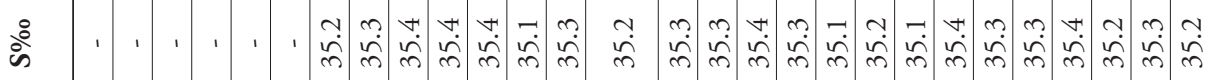

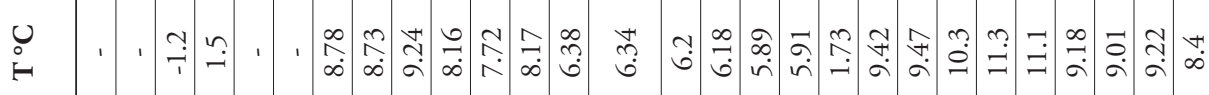

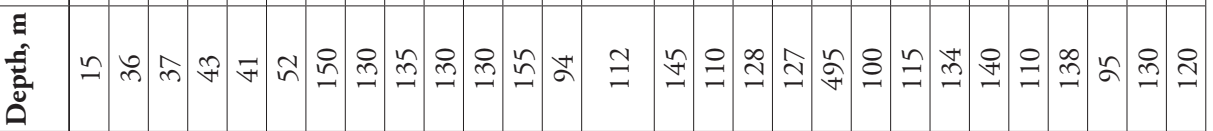

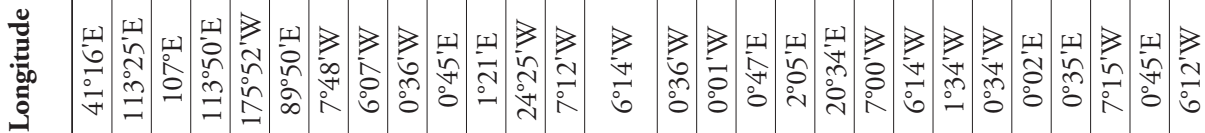

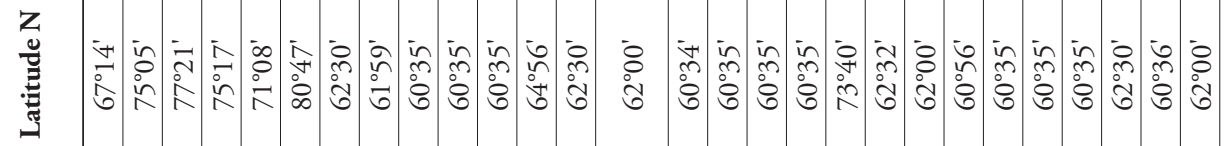

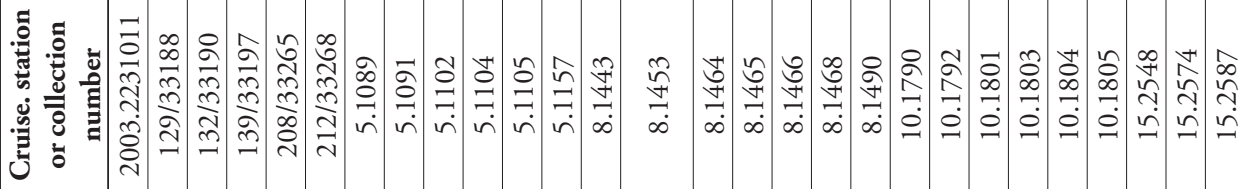

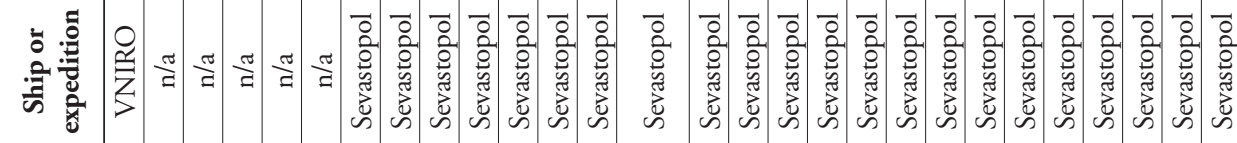

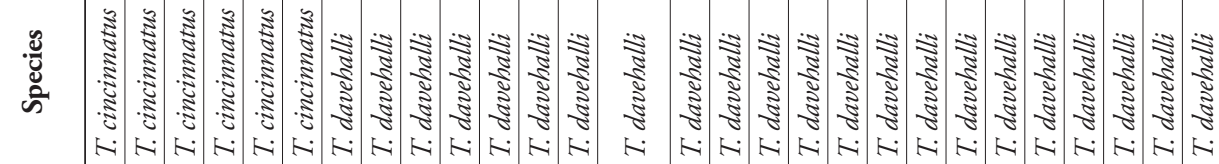




\begin{tabular}{|c|c|c|c|c|c|c|c|c|c|c|c|c|c|c|c|c|c|c|c|c|c|c|c|c|c|c|}
\hline 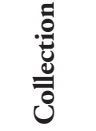 & & & $\begin{array}{l}Z \\
u \\
z \\
z\end{array}$ & 我 & $\begin{array}{l}n \\
0 \\
0 \\
z\end{array}$ & 象 & $\begin{array}{c}\infty \\
0 \\
v\end{array}$ & ) & 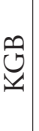 & 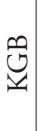 & 离 & 点 & : & $\begin{array}{c}0 \\
0 \\
ن\end{array}$ & $\begin{array}{l}0 \\
0 \\
v\end{array}$ & 包 & 包 & & $\frac{0}{4}$ & & $\begin{array}{c}a \\
v \\
v\end{array}$ & & 电 & जै & & 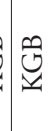 \\
\hline 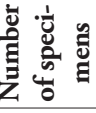 & $\sim$ & $N$ & $m$ & 6 & 후 & $\sim$ & $\sim$ & 6 & -1 & $\underset{*}{*}$ & -1 & $N$ & $N$ & - & $N$ & $v$ & $N$ & -1 & Ft? & $m$ & $+\Im$ & - & $-\stackrel{\sim}{ }$ & 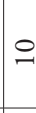 & in & 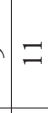 \\
\hline 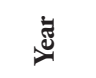 & Ә & กิ & 1 & $\stackrel{\approx}{\approx}$ & $\begin{array}{l}\stackrel{\unrhd}{\beth} \\
\stackrel{2}{2}\end{array}$ & ลิ & $\stackrel{\aleph}{\approx}$ & $\hat{\tilde{\approx}}$ & $\stackrel{\hat{n}}{\approx}$ & $\begin{array}{l}\hat{\approx} \\
\approx\end{array}$ & $\stackrel{\approx}{\approx}$ & $\stackrel{\tilde{\alpha}}{\stackrel{2}{\Xi}}$ & $\stackrel{\infty}{\bumpeq} \underset{\beth}{\beth}$ & $\stackrel{\infty}{\approx}$ & 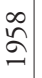 & $\begin{array}{l}\infty \\
\approx \\
\approx\end{array}$ & 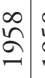 & $\begin{array}{l}\infty \\
\\
\underline{\Sigma}\end{array}$ & $\underline{\underline{\Sigma}}$ & 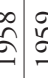 & $\tilde{\sigma} \delta \tilde{\sigma}$ & d & 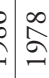 & જิ & $\stackrel{\widehat{\widehat{~}}}{\widehat{\Xi}}$ & $\stackrel{\widehat{\approx}}{\Omega}$ \\
\hline 葛 & 1 & $m$ & 1 & $=$ & ○ & $a$ & $\curvearrowright$ & $\wedge$ & $\wedge$ & $\infty$ & $\infty$ & $\infty$ & $n$ & $n$ & $m$ & $a$ & $\circ$. & $\circ$ & 0. & $=$ & $\exists=$ & $\infty$ & $0 \cong$ & - & - & 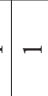 \\
\hline बि & & $\beth$ & 1 & $\beth$ & $\stackrel{m}{\sim}$ & $\vec{\sim}$ & $\simeq$ & $\stackrel{\infty}{\sim}$ & ¿ి & $\curvearrowright$ & $\curvearrowright$ & 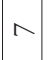 & $\approx$ & $\grave{\nu}$ & $\bar{n}$ & $\widehat{\imath}$ & $N$ & $\cong$ & 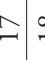 & $\stackrel{\infty}{\sim}$ & 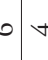 & $\infty$ & & W & $N$ & $a$ \\
\hline ळे & & 1 & 1 & $\begin{array}{c}a \\
\vec{m}\end{array}$ & $\stackrel{\text { ષे }}{\text { के }}$ & 1 & & $\begin{array}{c}\stackrel{+}{m} \\
\text {. }\end{array}$ & $\stackrel{g}{\text { mे }}$ & $\begin{array}{l}0 \\
\dot{n} \\
\text { n. }\end{array}$ & $\stackrel{\vec{m}}{\vec{p}}$ & $\begin{array}{c}0 \\
\dot{n} \\
\end{array}$ & ڤેं & $\underset{\vec{m}}{\stackrel{g}{d}}$ & के & 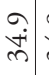 & 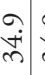 & के & $\begin{array}{l}0 \\
\vec{n} \\
\dot{m}\end{array}$ & \begin{tabular}{l|l}
$\vec{n}$ \\
$\vec{n}$
\end{tabular} & 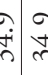 & 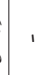 & & ' & 1 & \\
\hline : & 1 & ' & ' & 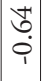 & $\begin{array}{l}\hat{\imath} \\
\stackrel{i}{i}\end{array}$ & \begin{tabular}{l}
\multirow{J}{*}{} \\
$\stackrel{-}{+}$
\end{tabular} & $\begin{array}{l}\stackrel{\rho}{\varphi} \\
1\end{array}$ & $\hat{\grave{\varphi}}$ & $\begin{array}{l}\infty \\
i \\
i\end{array}$ & $\begin{array}{l}\text { f. } \\
\stackrel{i}{i}\end{array}$ & $\begin{array}{l}\tilde{N} \\
\hat{i} \\
i\end{array}$ & $\begin{array}{c}\tilde{n} \\
\hat{i} \\
\hat{i}\end{array}$ & 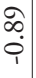 & $\mid \begin{array}{l}\infty \\
\infty \\
0 \\
\varphi\end{array}$ & $\grave{\varphi}$ & $\begin{array}{l}\stackrel{+1}{2} \\
\grave{1}\end{array}$ & $\begin{array}{l}\overrightarrow{0} \\
\dot{1} \\
\dot{1}\end{array}$ & 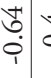 & 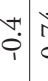 & & $\underset{1}{2}$ & 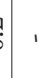 & & ' & 1 & \\
\hline 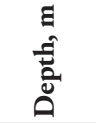 & $\stackrel{\circ}{\circ}$ & $\curvearrowright$ & 1 & 8 & $\stackrel{\infty}{\curvearrowleft}$ & $\begin{array}{l}0 \\
m \\
m\end{array}$ & 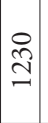 & $\widehat{\widehat{\imath}}$ & $\begin{array}{l}0 \\
\infty \\
\infty\end{array}$ & $\sqrt{6}$ & $\left|\begin{array}{l}n \\
0 \\
\infty\end{array}\right|$ & $\stackrel{2}{2}$ & $\stackrel{R}{\wedge}$ & : & స్ & $\underset{I}{\beth}$ & $\begin{array}{l}0 \\
\mathbb{N}\end{array}$ & 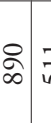 & $\bar{n}$ & $\vec{n}$ & $\begin{array}{l}0 \\
0 \\
n\end{array}$ & $\frac{n}{c}$ & hి & $\stackrel{f}{*}$ & 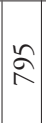 & No \\
\hline 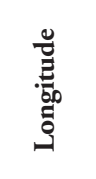 & 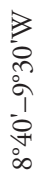 & 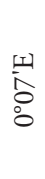 & & $\mid \begin{array}{c}1 \\
0 \\
8 \\
i n \\
\text { in }\end{array}$ & $\begin{array}{l}1 \\
8 \\
0\end{array}$ & 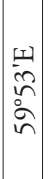 & $\begin{array}{l}3 \\
0 \\
\infty \\
\infty\end{array}$ & $\begin{array}{l}3 \\
\text { in } \\
\text { in }\end{array}$ & 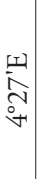 & $\begin{array}{l}8 \\
0 \\
\stackrel{8}{0} \\
\text { ते }\end{array}$ & 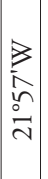 & $\mid \begin{array}{l}3 \\
1 \\
0 \\
0 \\
0 \\
\end{array}$ & 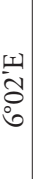 & $\begin{array}{l}3 \\
0 \\
0 \\
\infty \\
\infty\end{array}$ & 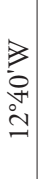 & 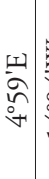 & 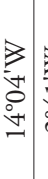 & 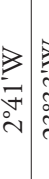 & 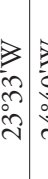 & 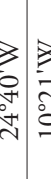 & 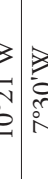 & $\begin{array}{ll}1 \\
0 \\
0 \\
0 \\
0 \\
0\end{array}$ & 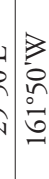 & $\begin{array}{l}8 \\
\infty \\
0 \\
0 \\
0 \\
\end{array}$ & 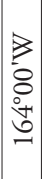 & ? \\
\hline
\end{tabular}

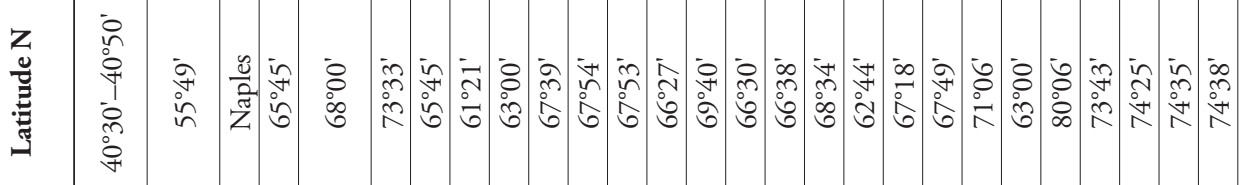

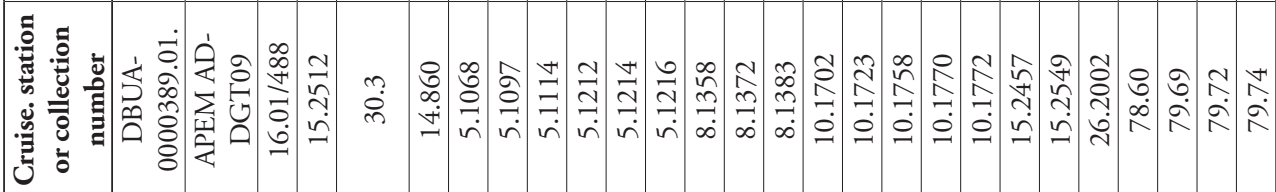

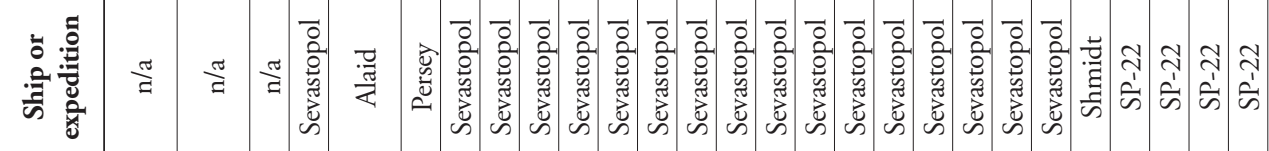

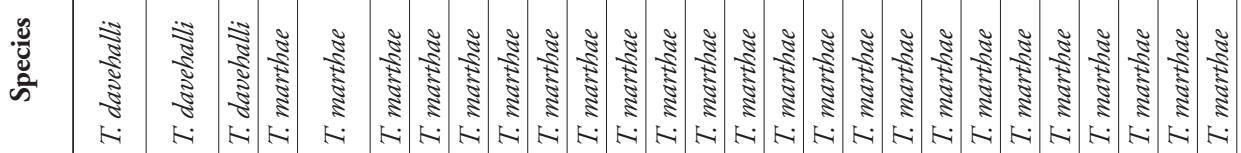




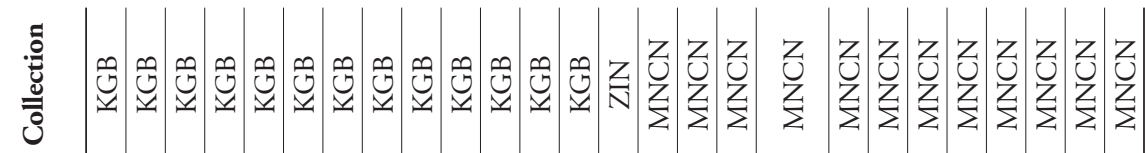

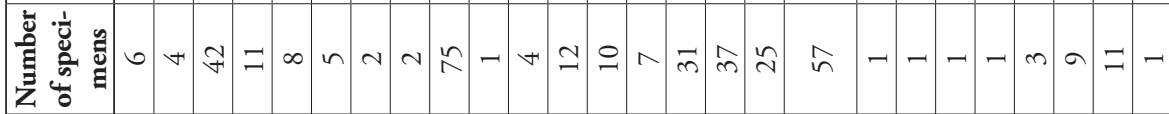

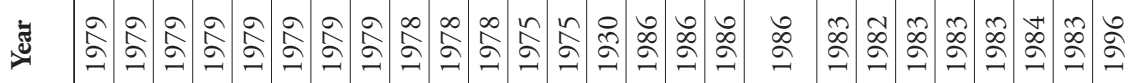

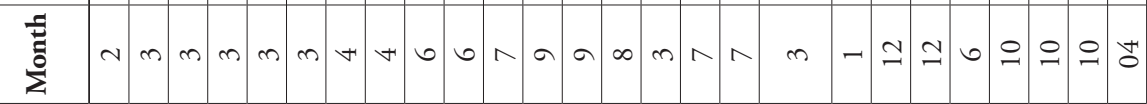

ఏ્ન

\&

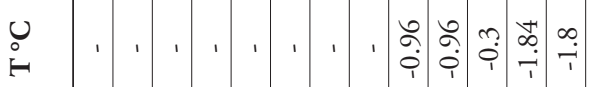

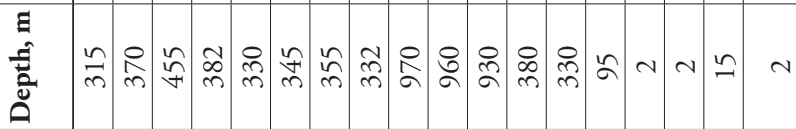

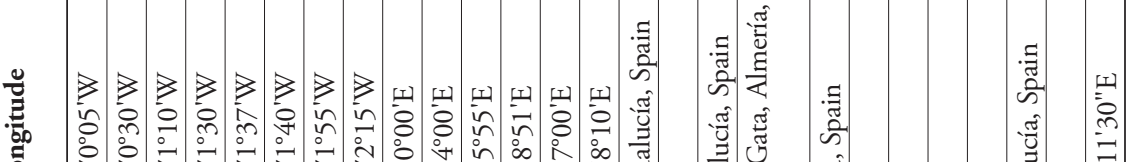

总

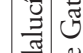

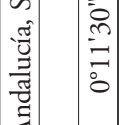

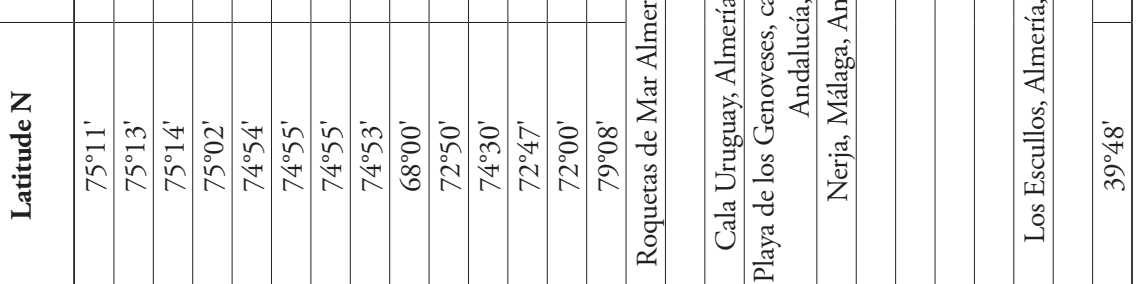

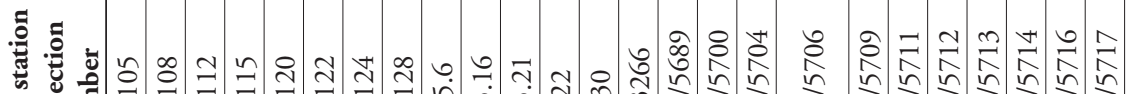

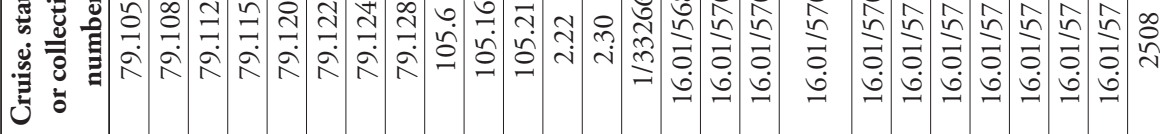

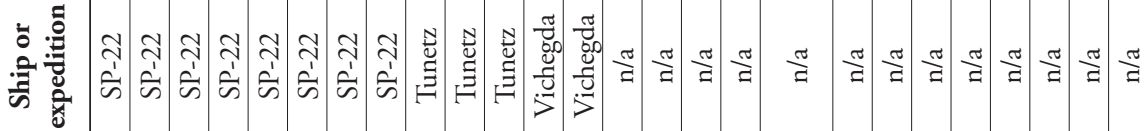

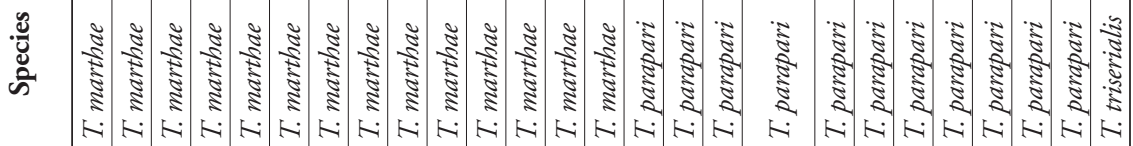


of the worm during fixation. I recommend using relative size (assessed by eye), as length depends on muscle retraction during fixation and furthermore worms often are incomplete posteriorly. Maximum size of the largest specimen was estimated for each sample or set of nearby samples as maximum size varies between distant samples, over a species range.

\section{Systematics}

\section{Terebellidae Johnston, 1846}

Read and Fauchald (2018) is followed in using the family rank Terebellidae rather than Thelepodidae.

\section{Thelepodinae Hessle, 1917}

\section{Thelepus Leuckart, 1849}

Type species. Amphitrite cincinnata Fabricius, 1780.

Diagnosis. Branchiae formed of numerous simple filaments arranged in more or less distinct parallel transverse rows arising from S2-S4; notochaetae from S3 (= BS2), uncini from C3 (= S5); lateral lobes absent.

Remarks. The genus includes 48 species (Hsueh and Li 2016), distributed from the Arctic to the Antarctic and from the littoral to abyssal zones. The most important taxonomic characters used for species separation based on Day (1955), Hutchings and Glasby (1987), and this study are:

The number of branchial segments. The number of BS varies from zero to three; most species have three BS. Only six species currently accepted as valid have two BS. Very little variation in the number of BS was observed; only one specimen amongst more than a thousand of all four species had a third branchia, on one side only. Of course, juveniles may have fewer BS, and some of the very small worms in the examined material had only one BS, or branchiae were absent. The final number of BS seems to appear when the size of the worm is approximately $1 \%$ of maximum.

The branchial fields from which the filaments arise. A distinct median gap and lateral extension of the filaments appears to be constant within a species, but in species with numerous filaments both tend to change with size: as the gap becomes narrower, the extension goes further laterally.

The number of branchial filaments. Some species have very few filaments in total, while others have many (10-40 or more). The number of filaments tends to increase with increasing size of the animal. Once adulthood is achieved, there is little variation in the number of filaments, independent of the size of the worms. According to our data, the maximum size of worms varies between localities for the same species, but 
the maximum number of filaments is relatively constant within a species. Hutchings and Glasby (1987) suggested that the relative number of branchial filaments between BS2, BS3, and BS4 is more important than the actual number of filaments. However, if there are only a few filaments, variation in their number leads to significant changes in the relative number of branchial filaments and this feature becomes unreliable.

The number of segments with notopodia and notochaetae. There are two groups of species within Thelepus: (1) notochaetae present only on the anterior half of the body; there are numerous fully-developed segments without notopodia that differ from notopodial segments only by the absence of notopodia, and (2) species with notochaetae present for most of the body, absent only in the segments clustered near the pygidium. This difference seems to be diagnostic.

The number of rows of uncini. Uncini can be in a single row or form a loop; all of the species investigated have a single row, but T. nucleolata Claparède, 1870, described from the Mediterranean (Gulf of Naples) has uncini forming a loop after S14. The species is poorly known and has not been recorded since the original description. The presence or absence of the loop seems to have high taxonomic value.

The shape of the uncinus. The most important features seem to be the shape of the prow, the position of the attachment button, and the arrangement of teeth above the main fang-forming crest. The last character is better seen in SEM photographs, whilst the first two are better observed using a compound microscope. Three of the four investigated species with two BS have very similar U1 uncini, but other species inhabiting European waters, T. setosus (Quatrefages, 1866) and T. triserialis (Grube, 1855), have very different uncini (Fig. 1B, C). The shape of the uncini may vary along the body; they usually decrease in size but, in T. parapari sp. n., the shape also changes. Therefore it is best to examine and compare uncini from a specified unciniger, such as $\mathrm{U} 1$; comparison of previously described uncini without detail of the segment of origin has limited value.

Presence/absence of eyespots. Hutchings and Glasby (1987) reported that, in some specimens of T. plagiostoma Schmarda, 1861 and T. robustus (Grube, 1878), eyespots may be absent. The species examined for this paper either have eyespots or not. Eyespots are sub-epithelial and disappear if the epithelium is macerated due to poor fixation.

Comparative size of notopodia. In some species, the first notopodia are distinctly underdeveloped (for example Fig. 4D), whilst other species have all anterior notopodia of almost equal size. However, this difference may only be apparent in large worms.

Notochaetae. The notochaetae of the four investigated species look very similar. The shape of the notochaetae is of limited taxonomic value, at least for the species examined here.

Tubes. The tubes of all the investigated species are constructed using local material (shell fragments, small stones, spicules etc.) without specificity. Tubes are also attached to larger substrata, usually stones, if possible. Some tubes have a branched crown very similar to that reported for Axionice conchilega (Pallas, 1766) by Holthe (1986); this was observed in material examined in this study from the Norwegian Sea. 


\section{Key to European Thelepus}

1

Two BS 2

- $\quad$ Three BS 6

2 Uncini in a single row throughout .3

- Uncini after S14 form loop T. nucleolata (Claparède, 1870) Notopodial segments present on 50-66\% of body length..... T. davehalli sp. n. Notopodial segments present on at least $90 \%$ of body length 4

Uncini of TU1 with one tooth above main fang .5

- $\quad$ Uncini of TU1 with two teeth above main fang T. parapari sp. $\mathrm{n}$. Eyespots numerous (may disappear if epithelium is macerated due to poor fixation) T. cincinnatus (Fabricius, 1780) Eyespots absent T. marthae sp. $\mathrm{n}$. Prow of uncinus well developed with a button above (Fig. 1B). Few branchial filaments..... T. triserialis (Grube, 1855)

- $\quad$ Prow of uncinus poorly developed (Fig. 1C). Numerous branchial filaments.... T. setosus (Quatrefages, 1866)

\section{Taxonomic remarks on European species}

Species identification is straightforward when examining a series of well preserved, complete specimens. However, single and incomplete specimens (posterior absent) are often encountered. For such specimens, the researcher should initially examine the presence/absence of eyespots and then the sample locality/habitat. This information is usually sufficient for precise identification for comparatively well preserved (fresh) material. A synopsis for all known species of Thelepus with two branchiferous segments is given in Table 2 .

\section{Thelepus cincinnatus (Fabricius, 1780), s. str.}

Figs 2, 3, 11, 12

Thelepus cincinnatus: type locality Greenland (probably Frederikshâb), type material probably never designated (Holthe 1986): ? Fauvel 1927: 271-272, fig. 95 i-m; Pettibone 1954: 327-328, fig. 37e, f; Zatsepin 1948: 154, table XXXVIII, 7 (partim); ?Hartmann-Schröder 1996: 528-530, Abb. 258; Holthe 1986: 140-142, fig. 63, map 62 (partim); Jirkov 2001: 526-527 (partim).

Material (Table 1): 413 specimens from 33 stations collected at $8-1350 \mathrm{~m}$, bottom temperature $-1.53-7.37^{\circ} \mathrm{C}$. Ten specimens from Alaid station 6 deposited at MNCN: $16.01 / 17777$.

Additional material. Thelepus antarcticus ZIN IV.1.2 (5 specimens) 
Table 2. Synoptic character data for all known species of the genus Thelepus with two branchiferous segments. Abbreviations: n.d. - absence of data.

\begin{tabular}{|c|c|c|c|c|c|c|c|c|c|}
\hline \multirow[b]{2}{*}{ Species } & \multirow[b]{2}{*}{$\begin{array}{l}\text { eyes- } \\
\text { pots }\end{array}$} & \multicolumn{2}{|c|}{ Filaments } & \multicolumn{2}{|c|}{ number of } & \multirow{2}{*}{$\begin{array}{l}\text { \% body } \\
\text { length } \\
\text { with } \\
\text { notopodia }\end{array}$} & \multirow[b]{2}{*}{ loop } & \multirow[b]{2}{*}{ type locality } & \multirow[b]{2}{*}{ source } \\
\hline & & BS1 & BS2 & segments & $\begin{array}{c}\text { pairs of } \\
\text { notopodia }\end{array}$ & & & & \\
\hline $\begin{array}{l}\text { T. antarcticus } \\
\text { Kinberg, } 1866\end{array}$ & yes & 15 & 12 & ca. 100 & ca. 100 & ca. $100 \%$ & no & Antarctica & $\begin{array}{c}\text { Benham } \\
\text { (1921); } \\
\text { present study }\end{array}$ \\
\hline $\begin{array}{l}\text { T. cincinnatus } \\
\text { (Fabricius, 1780) }\end{array}$ & yes & $<30$ & $<22$ & ca. 100 & $70-106$ & ca. $100 \%$ & no & $\begin{array}{l}\text { West Green- } \\
\text { land }\end{array}$ & $\begin{array}{c}\text { Pettibone } \\
1954 ; \\
\text { present study }\end{array}$ \\
\hline $\begin{array}{l}\text { T. crassibranchiatus } \\
\text { Treadwell, } 1901\end{array}$ & yes & 4 & 2 & n.d. & $>38$ & n.d. & n.d. & Puert & $\begin{array}{c}\text { Treadwell } \\
\text { (1901); } \\
\text { Londoño- } \\
\text { Mesa (2009) }\end{array}$ \\
\hline T. davehalli sp. n. & no & $<20$ & $<10$ & ca. 100 & $30-40$ & $1 / 2-2 / 3$ & no & $\begin{array}{c}\text { N-E Atlantic } \\
\text { shelf }\end{array}$ & present study \\
\hline T. ham & yes & 5 & 5 & 60 & 32 & $50 \%$ & ? & Pacific Alaska & Hilbig (2000) \\
\hline T. marthae sp. n. & no & $<10$ & $<5$ & ca. 100 & $<65$ & $90 \%$ & no & $\begin{array}{r}\text { deep } \\
\text { oce }\end{array}$ & present study \\
\hline $\begin{array}{l}\text { T. nucleolata } \\
\text { (Claparède, 1870) }\end{array}$ & yes & 6 & 4 & n.d. & n.d. & n.d. & yes & $\begin{array}{l}\text { Gulf of } \mathrm{Na}- \\
\text { ples, Italy }\end{array}$ & $\begin{array}{c}\text { Claparède } \\
(1870)\end{array}$ \\
\hline $\begin{array}{l}\text { T. pascua } \\
\text { (Fauchald, 1977) }\end{array}$ & no & 1 & 1 & n.d. & $>=32$ & n.d. & no & $\begin{array}{l}\text { Atlantic } \\
\text { Panama }\end{array}$ & $\begin{array}{c}\text { Fauchald } \\
\text { (1977); } \\
\text { Londoño- } \\
\text { Mesa (2009) }\end{array}$ \\
\hline T. parapari sp. n. & yes & $<11$ & $<8$ & ca. 70 & $<56$ & $95 \%$ & no & Mediterranean & present study \\
\hline
\end{tabular}

Description. Largest specimen $140 \mathrm{~mm}$ in length and $5 \mathrm{~mm}$ in width, although some fragments distinctly larger (up to $7 \mathrm{~mm}$ width); maximum size estimated at over $200 \mathrm{~mm}$; larger specimens had been collected at shallow depths, less than $100 \mathrm{~m}$. Number of segments increased with body size; number in investigated specimens: 113 .

Buccal tentacles numerous, equal to body length, grooved. Eyespots rounded subepithelial spots, black or dark brown, numerous, usually in several transverse rows on back of upper lip (Fig. 2A, B). Even smallest specimens $(<0.5 \mathrm{~mm}$ width R/V Sevastopol st. 1769) with numerous eyespots. Specimens from deepest sample (R/V Sevastopol, st. 1580, $1350 \mathrm{~m}$ ) also with numerous eyespots.

Branchial filaments numerous, long and tangled (Fig. 2A, C-G). Due to tangling it was impossible to count number of branchial filaments in large worms $(>5-6 \mathrm{~mm}$ width) without removing them one by one. Maximum number of BS1 filaments ca. 20-30, extending laterally to a point level with midpoint or lower edge of row of U1 uncini; outermost filaments usually 2-3 times shorter than those most developed. BS2 with a maximum of 15-20 filaments. One specimen (from Alaid 30.13) had four filaments on BS3 on right hand side of body; length of these was equal to notopodia of same segment. Filaments attached to a transverse elevated stump in 1-2 irregular rows depending on number of filaments. Number of filaments increases with body size; 

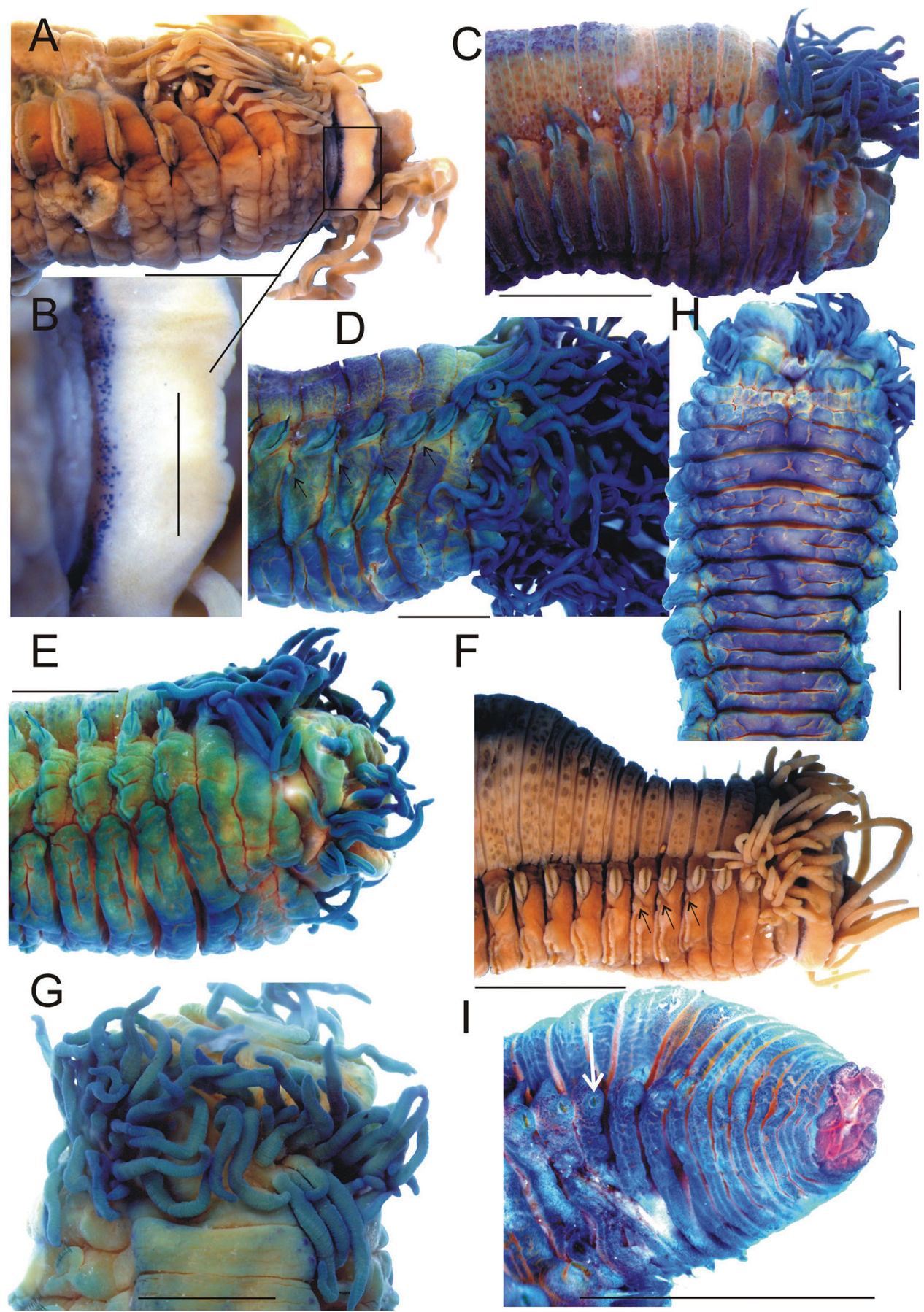

Figure 2. Thelepus cincinnatus external morphology. A, C-I lateral view of anterior end B detail, showing eyespots $\mathbf{G}$ dorsal view of anterior end $\mathbf{H}$ ventral view of anterior end $\mathbf{I}$ lateral view of posterior end (arrow indicates last segment with notochaetae). A, B, F, I Alaid st. 30.13 C Alaid st. 8 D, E, H, G Alaid st. 6. All worms except $\mathbf{A}, \mathbf{B}, \mathbf{F}$ stained with methylene blue $\mathbf{D}, \mathbf{F}$ arrow indicates nephridial papillae. Scale bars: $2 \mathrm{~mm}$ except $\mathbf{B} 0.5 \mathrm{~mm}$. 


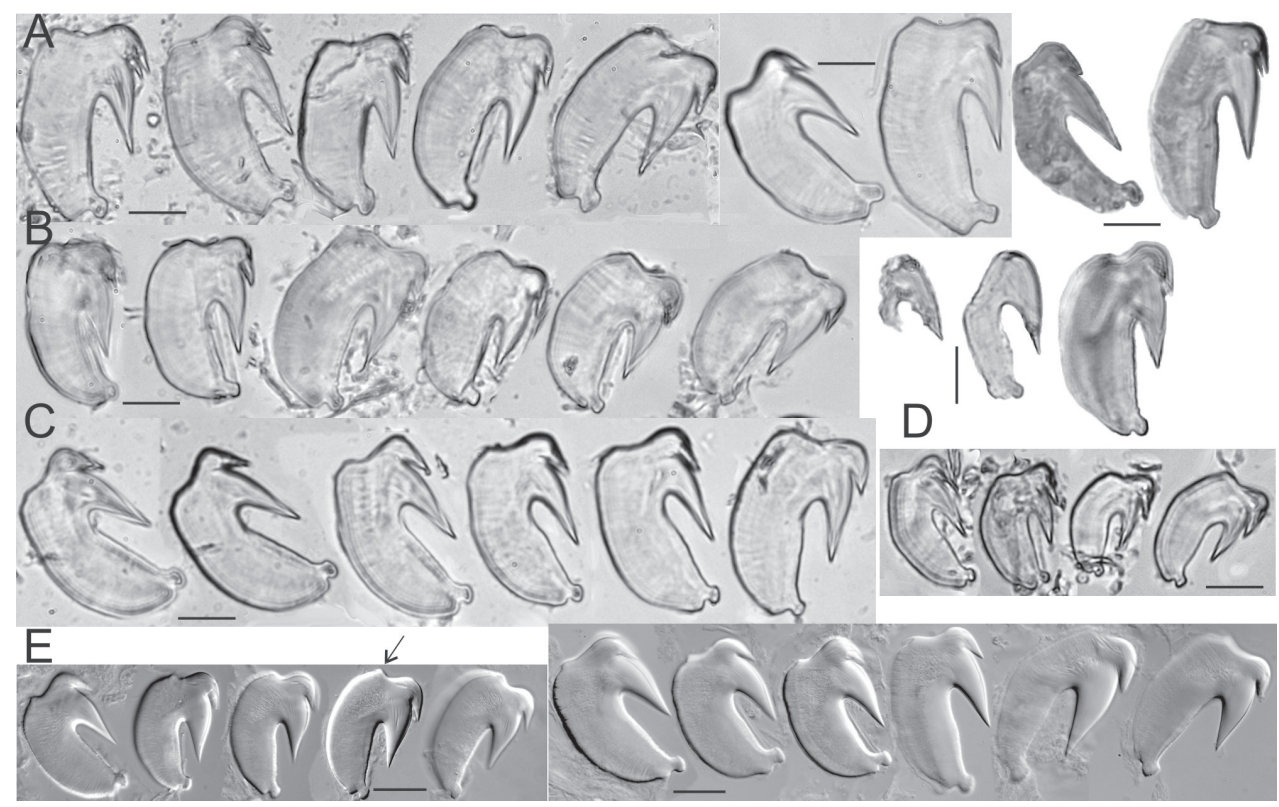

Figure 3. Thelepus cincinnatus and Thelepus antarcticus uncini. A Alaid 30.6 B Alaid 30.8 C, D Alaid 30.13 A-C uncini from U1 D uncini from posterior body E Thelepus antarcticus ZIN IV.1.2, arrow indicating hump, which is different from that in T. cincinnatus. Each block from one specimen, all uncini from TU1. Third block of $\mathbf{A}$ and second block of $\mathbf{B}$ shows stage of development of uncini. Scale bars: $20 \mu \mathrm{m}$.

small worms (1-2 mm width) have fewer than 10 filaments on BS1. Smallest specimen (Sevastopol 1769, width $<0.5 \mathrm{~mm}$ ) with no filaments. Extension of filaments laterally depends upon worm size, with filaments extending only to level of upper margin of uncinal row in small worms. Wide medial gap separating left and right groups of filaments. Lateral lobes absent. Dorsum with warts or subepithelial honeycomb, forming more or less regular rows (Fig. 2C, F); number of rows increases with size of segments and worm. Segmentation distinct. Ventrum glandular, more so with increased "wrinkling” (Fig. 2H). Poorly visible, small nephridial papillae on S4-S7 above neuropodia; those on S5-S7 largest and usually only ones visible (Fig. 2D, F, arrowed).

Notopodia commence from BS2, with anterior notopodia large and transverse. Notopodia raised on body surface or flattened, depending on whether fixation occurs whilst within or outside of tube. Notopodia of BS2 equal to or only slightly smaller than those most developed. Notopodia numerous and present on almost all segments except 10-20 posteriormost developing segments; in investigated material present on up to 106 segments. Last notopodia poorly developed, several times shorter than those most developed and almost without rami, with only a few notochaetae; last neuropodia also reduced (Fig. 2I). Part of worm without notopodia not exceeding 10\% of whole body length. Notochaetae in few (ca.10) anterior segments in two transverse rows: posterior row with long chaetae, distal half (winged part) becomes stained with methylene blue, anterior row with short chaetae; other notopodia with a single row of notochaetae. Notochaetae with narrow brims (Fig. 11B). 
Neuropodia from C3, tori increasing in size to U10, then becoming progressively shorter. Uncini in a single row with well-developed prow and crest and one tooth in profile (Fig. 3); within a neuropodium main fang develops first, crest develops later (Fig. 3D).

Pygidium with crenulated margin, without cirri or papillae.

Differential diagnosis. Morphologically, T. cincinnatus is closest to T. antarcticus Kinberg, 1866. The original description of T. antarcticus is very brief. The most complete re-description is by Benham (1921). It looks very similar to T. cincinnatus; however, I do not believe that it is the same species, since direct comparison of material from the northern and southern hemispheres is necessary to find differences. For the present time it can be stated that, although both species are of equal size (up to $200 \mathrm{~mm}$ length and $7 \mathrm{~mm}$ in diameter), T. cincinnatus has at least twice as many branchial filaments as T. antarcticus. The five specimens investigated (length up to $5 \mathrm{~cm}$ ) have no more than 15 branchial filaments on BS1, distinctly fewer eyespots and slightly different uncini, with a hump (Fig. 3E).

Thelepus cincinnatus differs from other new species described herein as indicated: from $T$. davehalli sp. $n$. by the presence of eyespots and the absence of numerous completely developed posterior segments without notopodia; from T. marthae sp. n. by the absence of eyespots and by the higher number of branchial filaments and segments with notopodia; and T. parapari sp. $\mathrm{n}$. has a crest of uncini on TU1 with two rows in profile, while $T$. cincinnatus has only one. Other species of Thelepus with two pairs of branchiae and eyespots have at least three times fewer branchial filaments and all but $T$. parapari sp. $\mathrm{n}$. have half the number of segments with notopodia (Table 2).

Remarks. The investigated material included almost 2000 specimens (from more than 100 stations) from the high Arctic to the Mediterranean, from depths between 2 $\mathrm{m}$ and almost $2 \mathrm{~km}$. The type locality of T. cincinnatus is outside the ranges of all investigated species, but $T$. cincinnatus $\mathrm{s}$. str. investigated specimens perfectly agree with the description of topotypes (Pettibone 1954). It is supposed that Pettibone's description is that of the true T. cincinnatus.

In some samples, specimens lacked eyespots; however, this is likely to be due to fading because specimens in same samples (with several specimens present) have eyespots, but they are paler, smaller and less numerous than is typical. This fading seems to depend on preservation method: all material with faded eyespots had been stored in formalin for over ten years. The age of samples does not influence fading significantly; although all specimens without eyespots were collected over 50 years ago, other specimens collected a century ago and kept in alcohol had retained eyespots. So absence of eyespots should not be considered to be a characteristic of this species.

Three subspecies (varieties according to original descriptions) of $T$. cincinnatus have been described (Bellan 2008) and, based on the discussion below, none are considered valid.

Thelepus cincinnatus var. andreanae McIntosh, 1922. McIntosh wrote "dorsal cephalic collar with eye-specks"; as all other Thelepus with two pairs of branchiae from the area near the type locality also lack eyespots, this name should be accepted as a junior synonym of T. cincinnatus s. str. as believed by Bellan (2008). 
Thelepus cincinnatus var. canadensis McIntosh, 1885; has eyespots according to the original description. Type locality: $43^{\circ} 04^{\prime} \mathrm{N}, 64^{\circ} 05^{\prime} \mathrm{W}, 51 \mathrm{fms}$. Specimens collected near the type locality of this subspecies (R/V "Persey-3" see Table 1 ) did not show differences from other specimens, confirming Hartman's (1959) acceptance of T. cincinnatus var. canadensis as a junior synonym of the stem subspecies.

Thelepus cincinnatus var. profundus Roule, 1896. The description is too short to be informative: 'Un seul individu, différant du type par sa taille e plus petite, par son tube plus mince et couvert extérieurement d'un enduit peu épais formé de vase grise, et par la forme de ses plaques onciales; ces dernières sont plus étroites, et leurs trois dents plus espacées'. No figures are given so it is impossible to determine which species he was describing and as no type material was deposited in Paris (Solís-Weiss et al. 2004) this subspecies should be treated as a nomen dubium.

Other literature reports of Thelepus cincinnatus include:

Fauvel (1927) reported for T. cincinnatus; "nombreux points oculiformes"; however, most or all the area covered by the "Faune de France" seems to lie outside the range of T. cincinnatus, but includes the range of T. parapari sp. n. with eyespots, so he probably observed $T$. parapari sp. n.

Zatsepin (1948) and Holthe (1986); despite their descriptions agreeing well with $T$. cincinnatus s. str., they probably observed the other species described here, because these species' ranges fall within those covered by their papers. The same is true for our papers (Jirkov 2001; Jirkov and Leontovich 2013), where we overlooked T. marthae sp. n., T. davehalli sp. n., and T. parapari sp. n. but, in this case, it is supported by reinvestigation of the material.

Hartmann-Schröder (1996) reported eyespots for T. cincinnatus (Abb. 258), but her figures showed too few branchial filaments and no visible eyespots (they cannot be confirmed or observed in the figure shown). Either the specimen in the figure is too young (there is no scale) or she was studying a different species.

\section{Thelepus davehalli sp. $\mathrm{n}$.}

http://zoobank.org/7F969CCC-1770-4B35-9373-2271D9876ACC

Figs 4, 11

Material (Table 1): 444 specimens from 27 stations, collected at depths from 94-495 $\mathrm{m}, 1.73{ }^{\circ} \mathrm{C}-11.3{ }^{\circ} \mathrm{C}$. Holotype st. Sevastopol 2587. Material is deposited at the KGB, three paratypes from Sevastopol st.1453 are deposited at the MNCN 16.01/17772. Material from Aveiro (DBUA0000389.01) and Naples (MNCN 16.01/488) is not included in the type series as it was collected too far away from the type locality, despite seeming to be morphologically identical.

Description (based on holotype and paratypes). Holotype with 97 segments, 32 segments with notopodia, $95 \mathrm{~mm}$ length. Paratypes up to $100 \mathrm{~mm}$ long and $5 \mathrm{~mm}$ wide; number of segments increased with body size, up to 91 .

Several tens of grooved buccal tentacles as long as half body length. Eyespots absent. Branchial filaments numerous, long and tangled (Fig. 4A, C). Due to tangling, 


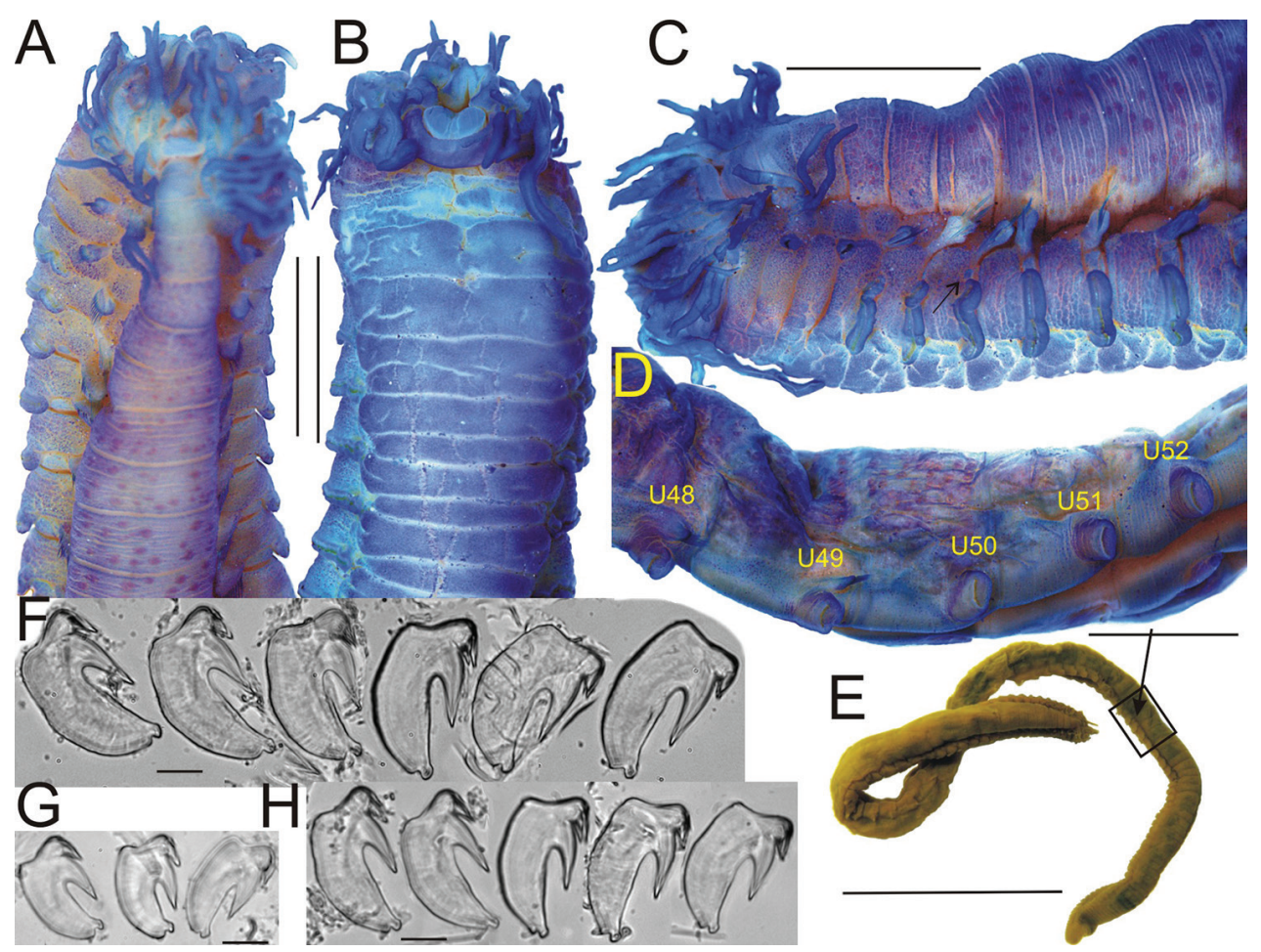

Figure 4. Thelepus davehalli sp. n. A-C anterior end: $\mathbf{A}$ dorsal view $\mathbf{B}$ ventral view $\mathbf{C}$ lateral view (arrowed nephridial papilla) D U48-U52 lateral view $\mathbf{E}$ - total view, rectangle shows position of $\mathbf{D}$ (arrow indicates last segment with notochaetae) F-H uncini: F, G U1 H U48, A-F, H Sevastopol st. 2587: A-E holotype $\mathbf{F}, \mathbf{H}$ paratype $\mathbf{G}$ APEM 232335. All worms but $\mathbf{E}$ stained with methylene blue. Scale bars: $2 \mathrm{~mm}(\mathbf{A}-\mathbf{E})$; $20 \mu \mathrm{m}(\mathbf{F}-\mathbf{H})$.

it was impossible to count number of branchial filaments in large worms $(>5-6 \mathrm{~mm}$ width) without removing them one by one. Maximum number of BS1 filaments ca. 20 (13 in holotype), extending laterally to a point level with upper edge of row of U1 uncini. BS2 with ca. ten filaments (nine in holotype). Filaments attached to a transverse elevated stump in 1-2 irregular rows but, due to numerous filaments, there appear to be more rows. Number of filaments increases with body size; small worms $(1-2 \mathrm{~mm}$ width) with ca. 5 filaments on BS1. Lateral extension of filaments depends upon worm size: in small worms, filaments extend only to a point level with notopodia. Lateral lobes absent. Dorsum with warts or subepithelial honeycomb, forming more or less regular rows (Fig. 4A, C); number of rows increases with size of segments and worms. Segmentation distinct. Nephridial papillae on S5-S7 above neuropodia (Fig. 4C, arrowed), usually poorly visible or not visible; papillae on $S 4$ apparently absent. Ventrum glandular, with "wrinkling" (Fig. 4B) increasing with worm size.

Notopodia from BS2. In small worms, more or less similar, almost cylindrical; in large worms, anterior notopodia transversely flattened, those in first few anterior segments several times smaller than those that are most developed (Fig. 4). Largest speci- 
mens in each sample with about 30-40 segments with notopodia, the smallest with fewer, but even specimens ten or more times smaller than largest (by size) with over 30 ; the next 40-60 segments without notopodia, i.e. about 1/3-1/2 of body length without notopodial segments. Notochaetae with narrow brims (Fig. 11A).

Neuropodia from C3; tori increasing in size to U10, then becoming progressively smaller. Uncini in a single row, uncini of U1 with well-developed prow and crest with one tooth in profile (Fig. 4F, G); posterior uncini (U48) very similar (Fig. 4H).

Pygidium with crenulated margin, without cirri or papillae.

Differential diagnosis. Only one previously known species, T. pascua (Fauchald, 1977) from the Atlantic coast of Panama, has two pairs of branchiae and no eyespots. It differs from T. davehalli sp. n. in its lower number of branchial filaments: single filament in BS1 and BS2 in T. pascua; up to 20 filaments in BS1 and up to 10 filaments in T. davehalli. Only one previously known species, T. hamatus Moore, 1905 from Pacific Alaska, has two pairs of branchiae and segments of the posterior half of the body without notopodia. It differs from $T$. davehalli in the presence of eyespots and a lower number of branchial filaments: five in BS1 and BS2 in T. hamatus; up to 20 filaments in BS1 and up to 10 filaments in $T$. davehalli. Thelepus davehalli differs from the other species described in this paper and other known species with two pairs of branchiae in the presence of fully developed segments without notopodia in the posterior $1 / 3-1 / 2$ of the body.

The last biramous parapodia of Thelepus davehalli is well developed (not reduced), following uniramous parapodia with well-developed neuropodia, contrary to other species described in this study (Fig. 4D, E). Anterior segments lack well-developed notopodia, contrary to those in $T$. cincinnatus and T. marthae.

Remark. Thelepus cincinnatus var. andreanae McIntosh, 1922 was described from within the range of $T$. davehalli. However, McIntosh clearly stated "Dorsal cephalic collar with eye-specks" while this new species has no eyespots.

Etymology. The species is named after my friend Mr. David Hall, Head of Marine and Freshwater Laboratories, Associate Director APEM Ltd., UK (Fig. 5).

\section{Thelepus marthae sp. $\mathrm{n}$.}

http://zoobank.org/10A8FCD4-3C8D-4B71-B5C6-341403C7F10E

Figs 6, 7, 11C

Thelepus cincinnatus: Zatsepin 1948: 154, table XXXVIII, 7 (partim); Jirkov 2001: 526-527 (partim) - non Fabricius 1780.

Material (Table 1): 921 specimens from 38 stations collected from depths between 95-1,510 m, bottom temperature $-1.84-2.8{ }^{\circ} \mathrm{C}$. Holotype: R/V Tunetz cruise 105 station 6. Material is deposited at the KGB, fifteen paratypes from Alaid st. 6 are deposited at MNCN 16.01/17773, seven paratypes are deposited at ZIN 1/33266.

Description (based on holotype and paratypes). Holotype with 81 segments, 55 segments with notopodia, $55 \mathrm{~mm}$ length. Paratypes up to $80 \mathrm{~mm}$ in length, 6-7 $\mathrm{mm}$ in 


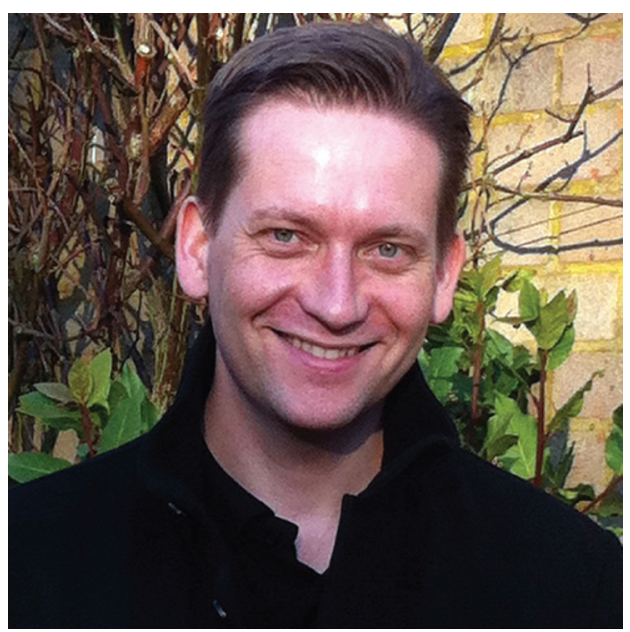

Figure 5. David Hall. The photograph was taken by his eldest daughter, Tara Hall.

width, 100 segments, last segments still in formation and clustered, not fully developed, with poorly-developed neuropodia, so not possible to count total number of segments.

Several tens of buccal tentacles, their length in fixed specimens equal to half of body length. Eyespots absent (Fig. 6A-C). BS1 with up to ten filaments (seven in holotype); BS2 with up to five (four in holotype) (Fig. 6F, H). Number of filaments increases with worm size; smallest worms, width $<1 \mathrm{~mm}$, with either no branchiae or with 1-2 filaments on BS1 and none on BS2. However, maximum number of filaments constant in different samples (containing sufficient worms) despite a range of maximum worm sizes across the samples. For example, largest worms from sample SP-22 st. 60 are at least three times larger than those from sample Alaid st. 3, but maximum number of filaments observed is same. Branchial filaments of BS1 extend laterally from level of notopodia of $\mathrm{C} 1$, to a maximum level with upper margin of uncinal row of U1. Filaments attached in a single row on an elevated stump. A wide medial gap separates left and right groups of filaments. Lateral lobes absent. Barely visible nephridial papillae on S4-S7 above neuropodia (Fig. 6A, B arrowed), in most specimens, few papillae visible, usually none. Ventrum glandular, with "wrinkling" (Fig. 4B) increasing with worm size (Fig. 6G).

Notopodia from S3, anterior notopodia almost cylindrical. Notopodia on C1, often $\mathrm{C} 2$, and sometimes $\mathrm{C} 3$ two to three times smaller than most developed notopodia (app. C10), sometimes one notopodium on C1 absent (Sevastopol 1358). Most developed notopodia transversally flattened, then reduced in size and become cylindrical again. In the most posterior segments notopodia very small; notochaetae present but several times shorter than most developed ones with no more than 10 per ramus; neuropodia also reduced to small pinnuli with few uncini. Notochaetae absent in 20-40 developing segments near pygidium (Fig. 6E); exact number difficult to determine as both annulation and neuropodia poorly developed. Some specimens also without 


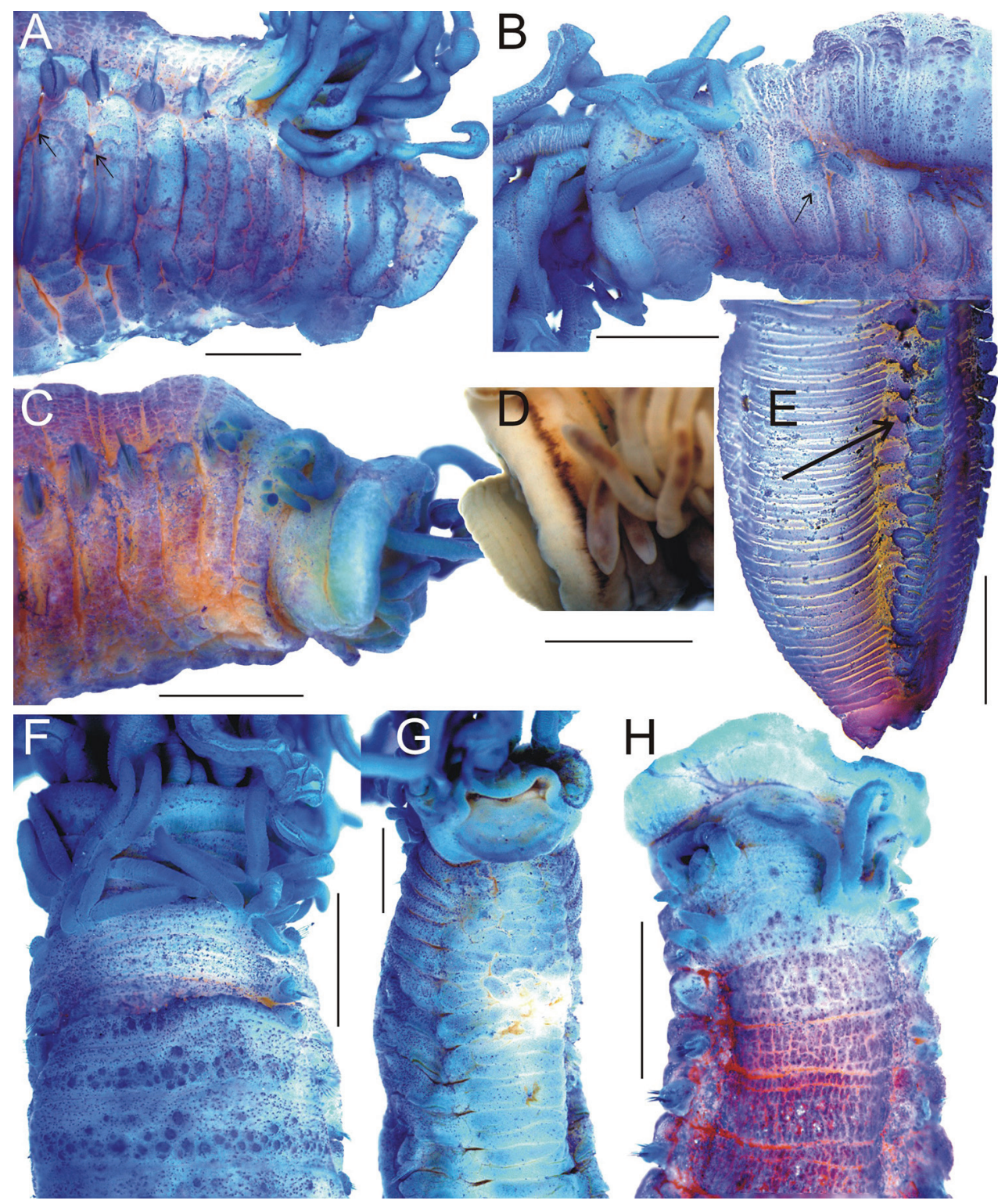

Figure 6. Thelepus marthae sp. n. external morphology. A-C lateral view of anterior end (arrowed nephridial papillae) $\mathbf{D}$ detail of anterior end, showing pigmented eyespots $\mathbf{E}$ lateral view of posterior end (arrowed last segment with notochaetae) $\mathbf{F}, \mathbf{H}$ dorsal view of anterior end $\mathbf{G}$ ventral view of anterior end. A SP-22 st.60 B, F, G holotype C, H Alaid 30.3 D, E SP-22 st. 72 . Scale bars: 1 mm. All worms but D stained with methylene blue.

notopodia on the 10-20 preceding reasonably well-developed segments. Number of segments with notopodia around 60 (in few complete worms available for this species), with several posterior segments lacking notopodia. However, segments without notopodia form only ca. $10 \%$ of the total worm length. Notochaetae of anterior segments 


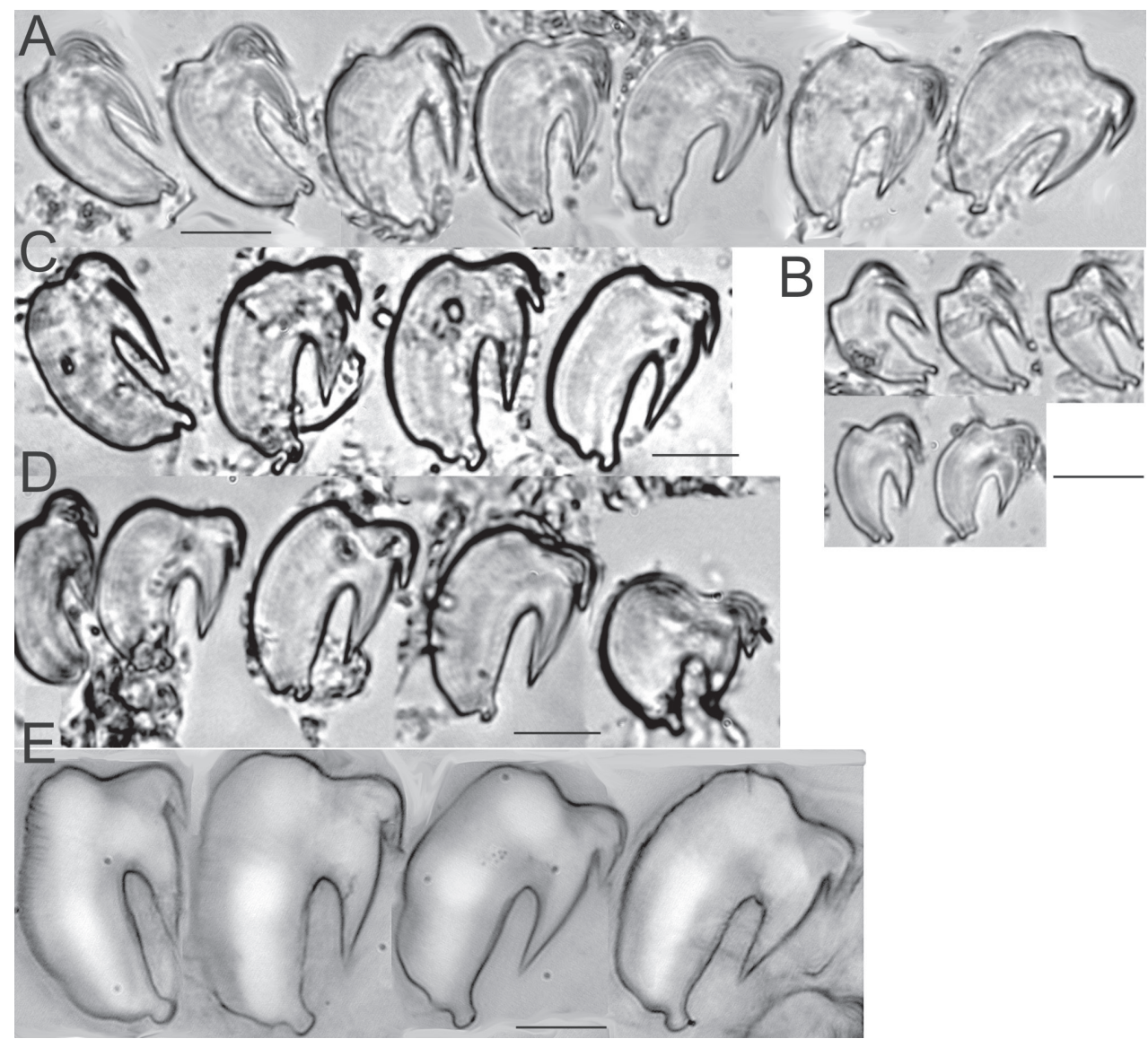

Figure 7. Thelepus marthae sp. n. uncini. A, B - Tunetz 105.6 C, D Alaid 30.3 E SP-22 60. A, C-E uncini of U1 B uncini of U20 from the pygidium. Each block from one specimen. Scale bars: $20 \mu \mathrm{m}$.

two to three times longer than notochaetae of posterior segments. Notochaetae in two transverse rows: anterior row with short chaetae, distal half (winged part) becomes stained with methylene blue, posterior row with long chaetae. Notochaetae with narrow brims (Fig. 11C).

Neuropodia from C3; tori increasing in size to U10, then becoming progressively slightly shorter. Uncini in single row. Uncini of U1 with well-developed prow and crest with one tooth in profile (Fig. 7A, C-E), posterior uncini (U20 from pygidium) very similar (Fig. 7B).

Pygidium with crenulated margin without cirri or papillae (Fig. 6E).

Differential diagnosis. Only one previously known species, T. pascua (Fauchald, 1977) from the Caribbean coast of Panama, has two pairs of branchiae and no eyespots. It differs from T. marthae in the lower number of branchial filaments: single filament in BS1 and BS2 in T. pascua; up to 20 filaments in BS1 and up to 10 filaments in T. marthae. Thelepus marthae differs from T. davehalli (described above) in the 
typically observed absence of fully developed segments without notopodia; if present, they form no more than $10 \%$ of the body length. Thelepus marthae differs from T. crassibranchiatus Treadwell, 1901, T. hamatus Moore, 1905 and T. pascua (Fauchald, 1977) (which have eyespots) in the higher number of branchial filaments and segments with notopodia. Thelepus marthae differs from T. cincinnatus and T. antarcticus in the lower number of branchial filaments and segments with notopodia. Thelepus marthae differs from $T$. parapari in the shape of its uncini.

Remark. One specimen (SP-22 st. 72) has numerous spots (Fig. 6D); together forming a transverse row, as with typical eyespots but, in this case, each individual spot is longitudinal instead of rounded as in T. cincinnatus (Fig. 2B) and other Terebellidae. These spots are in the same place as eyespots, but their very unusual shape makes their interpretation as eyespots doubtful; other interpretations are possible.

Etymology. Species is named after my friend Dr. Martha K. Leontovich (Fig. 8); she has described several new terebellid species.

\section{Thelepus parapari sp. n.}

http://zoobank.org/8B263E58-716A-4994-B773-E360665853B8

Figs 9, 11D

Material (Table 1): 177 specimens from 11 stations collected 26.03 .1986 between rhizomes of Posidonia, coralligenous formations, calcareous concretions and under stones, 2-15 m, Andalusia, Spain. Holotype MNCN 16.01/17774 (previously part of MNCN 16.01/5706), 5 paratypes previously deposited in MNCN 16.01/5706 now deposited in KGB.

Description (based on holotype and paratypes). Holotype with 58 segments, 50 of them with notopodia, $50 \mathrm{~mm}$ length. Paratypes up to $60 \mathrm{~mm}$ in length, $2 \mathrm{~mm}$ in width, 60-70 segments, posterior segments clustered and developing with poorlydeveloped neuropodia, so not possible to count total number of segments.

Several tens of buccal tentacles, their length in fixed specimens equal to half of body. Eyespots absent in most specimens (Fig. 9A), only some with reddish eyespots forming a band without dorsal gap (Fig. 9B). Eyespots probably fade during preservation or variation in this character. Preserved body uniformly beige to yellowish, without distinct patterns of pigmentation; one specimen with eyespots with reddish spots around branchiae. BS1 with up to 12 filaments (11 in holotype); BS2 with slightly fewer filaments (eight in holotype; generally, $>70 \%$ number on BS1). Filaments thin and very long, reaching more than half of corresponding segment's width (Fig. 9A, C). Number of filaments increases as worm grows; smallest observed worms (width $<0.5$ $\mathrm{mm}$ ) with 1-2 filaments on BS1 and one on BS2. Branchial filaments of BS1 attach in an irregular row on a slightly elevated stump and extend laterally to a point level with notopodia of $\mathrm{C} 1$ or sometimes level with upper margin of uncinal row of C3. Filaments of BS2 do not reach notopodia and usually form two rows. A wide medial gap separates left and right groups of filaments. Lateral lobes absent. 


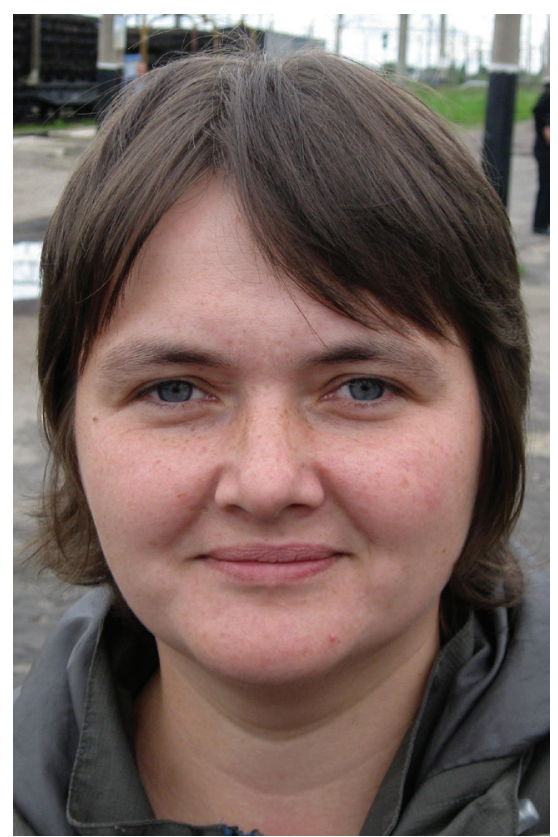

Figure 8. Dr. Martha K. Leontovich. The photograph was taken by the author.

Notopodia commence from S3, almost cylindrical anteriorly; those from $\mathrm{C} 1$ onwards of equal size. Posterior notopodia poorly developed (almost no rami), with few notochaetae that are several times shorter than most developed notochaetae; neuropodia also reduced. Notochaetae absent only in developing segments near pygidium, approximately ten such segments, exact number difficult to determine as both annulation and neuropodia poorly developed (Fig. 9D). Characteristic number of segments with notopodia less than 60 (based on few available complete worms). Segments without notopodia from only ca. $5 \%$ of total worm length. Relatively distinct (in comparison with species described above), small nephridial papillae on S4-S7, above neuropodia (Fig. 9A). Ventrum glandular, without distinct pads (Fig. 9A, E).

Notochaetae sometimes form two distinct transverse rows: anterior row with short chaetae, posterior row with longer chaetae, distal half (winged part) becomes stained with methylene blue, but usually in one row with mixed short and long chaetae; flanges appear to be wider than in species described above (Fig. 11D).

Neuropodia from C3, tori. Uncini in a single row. Uncini of U1 with two teeth in profile above main fang, unlike three species described above (Fig. 9F). However, posteriorly, uncini have only one tooth in profile, in common with species described above (Fig. 9G).

Pygidium with crenulated margin, without cirri or papillae.

Differential diagnosis. Only one previously known species, T. pascua (Fauchald, 1977), from the Caribbean coast of Panama has two pairs of branchiae and no eyespots. It differs from T. parapari in the lower number of branchial filaments: single 


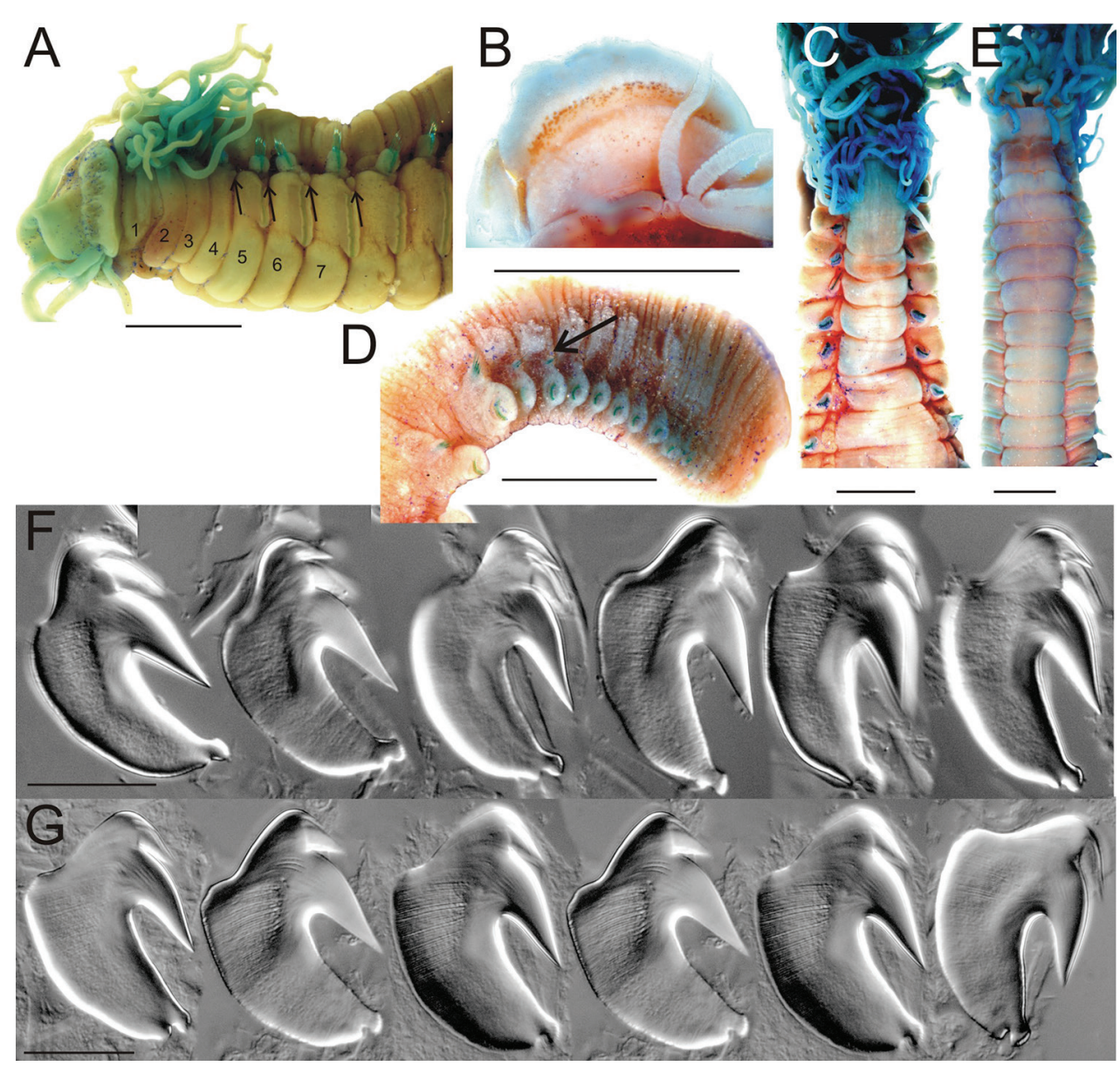

Figure 9. Thelepus parapari sp. n. A lateral view of anterior end (numbers of $S$ are shown, nephridial papillae arrowed) B detail of anterior end, showing pigmented spots $\mathbf{C}$ dorsal view $\mathbf{D}$ view of posterior end (arrowed last segment with notochaetae) E ventral view F U1 uncini G U25 uncini. A, C-E holotype B MNCN 5700 F-H MNCN 5706. All worms stained with methylene blue. Scale bars: $1 \mathrm{~mm}(\mathbf{A}-\mathbf{E}) ; 20 \mu \mathrm{m}(\mathbf{F}, \mathbf{G})$.

filament in BS1 and BS2 in T. pascua; up to 11 filaments in BS1 and up to 8 filaments in T. parapari. Thelepus parapari differs from T. davehalli (described above) in the absence of fully-developed segments without notopodia. Thelepus parapari differs from T. crassibranchiatus Treadwell, 1901, T. hamatus Moore, 1905 and T. pascua (Fauchald, 1977) (all of which have eyespots) in the higher number of branchial filaments and segments with notopodia. Thelepus parapari differs from T. cincinnatus and T. antarcticus in the lower number of branchial filaments and segments with notopodia. Thelepus parapari differs from T. cincinnatus and T. marthae (described above) in the shape of the uncini of U1. Thelepus nucleolata (Claparède, 1870), as Heterophenacia nucleolata, was described from nearby (Gulf of Naples), but T. parapari has uncini in a single row, whilst in T. nucleolata they form two rows.

Etymology. Species is named after my friend Dr. Julio Parapar, Universidade da Coruña, Spain (Fig. 10). 


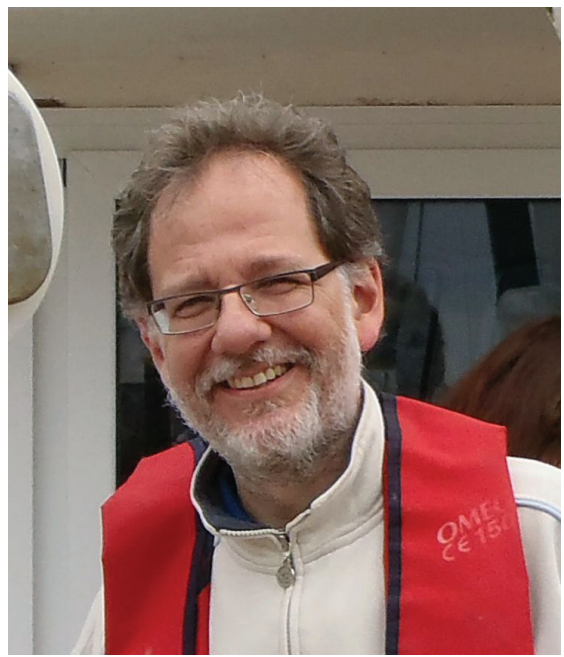

Figure I0. Dr. Julio Parapar. The photograph was taken by Dr. Juan Moreira.

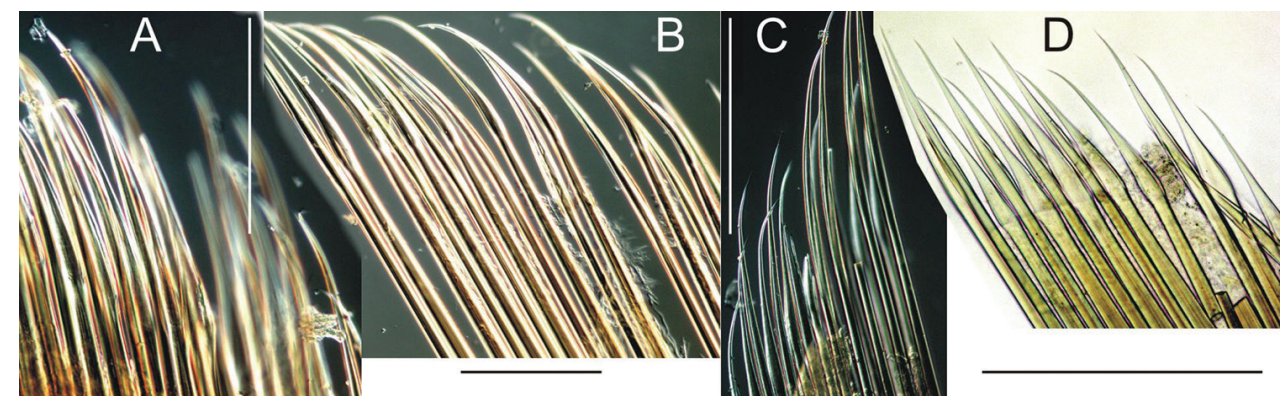

Figure II. Notochaetae of Thelepus. A T. davehalli B T. cincinnatus C T. marthae D T. parapari. Scale bars: 0.25 mm. A Sevastopol 15.2587 C7 B Alaid 30.6 C4 C Tunetz 105.6 C9 D MNCN 5706 C10.

\section{Discussion of species ranges}

Species range is a good character to assist with identification. Taxonomically similar species may have different, usually complimentary, ranges and, in this instance, the number of differing ranges is few. Usually, a species' range lies within a limited suite of ecological characters; for example, it is unlikely that the same species inhabits both intertidal and abyssal zones. On first impression, it seems that the ranges of the four species described here overlap (Fig. 12); however, in reality they are complimentary. Obviously T. cincinnatus s. str. is not a cosmopolitan species and it is even less widely distributed than previously supposed. Its range is limited to northern boreal and Arctic regions at least to the Chukchi Sea. In the Norwegian and Barents Seas and near Newfoundland, it was found at shelf depths from 8 to $200-400 \mathrm{~m}$; in the North Atlantic south of Iceland, it occurs deeper at least up to $1300 \mathrm{~m}$, so it can be expected south 


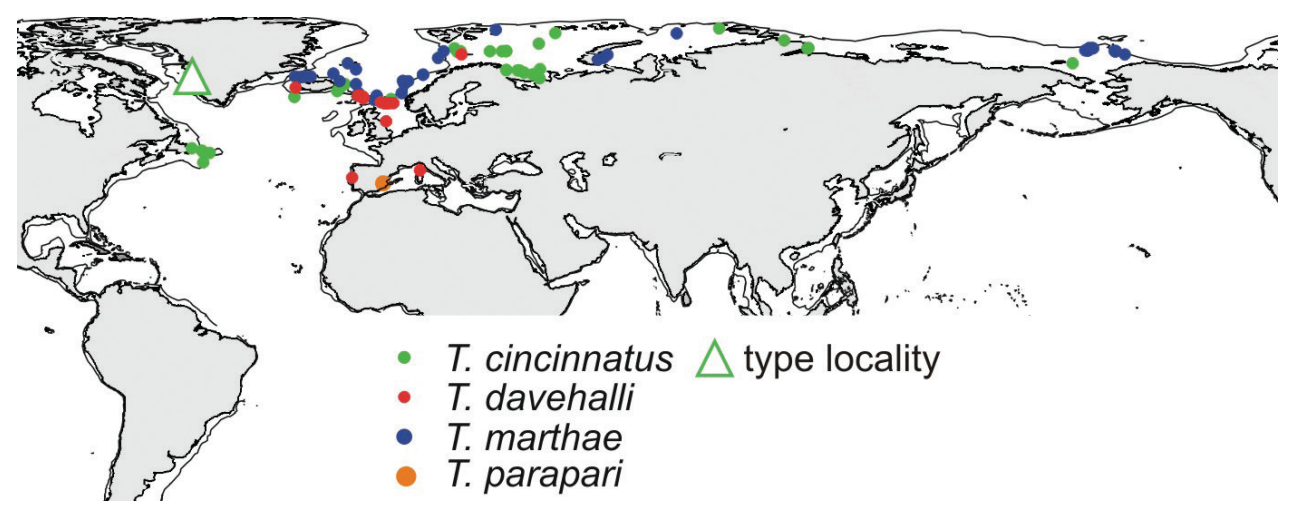

Figure 12. Map showing records of Thelepus. 500-m isobath is shown.

of Newfoundland at similar depths, in the high Arctic it is limited to shelf. I have not yet studied material from the Pacific Ocean, but as it was found in the Chukchi Sea, T. cincinnatus s. str. would be expected to occur in the North Pacific and it was reported by Uschakov (1955), Imajima and Hartman (1964) and Hobson and Banse (1981). Such a range (pers. obs.) is very usual in polychaetes and other benthic taxa. According to this study, at shelf depths to the south, $T$. cincinnatus is replaced by $T$. davehalli and, to the north, by T. marthae. Thelepus marthae also inhabits the Arctic slope from the Norwegian Sea to the slope of the Chukchi Sea but depth itself is not the limiting factor for the range: T. marthae can be found as shallow as $95 \mathrm{~m}$ in parts of the shelf nearby the slope. So ranges of $T$. cincinnatus and $T$. marthae are overlapping by depth limits, but not overlapping spatially. The fourth species previously identified as T. cincinnatus, T. parapari, inhabits upper sublittoral habitats in the Mediterranean (between the tidal front and the shore); in deeper water, below the tidal front, it is replaced by $T$. davehalli.

Of the other Thelepus species with two pairs of branchiae, T. antarcticus is limited to the Southern Ocean, T. crassibranchiatus and T. pascua are tropical west Atlantic species; the ranges of these species are significantly geographically removed from those of the species described here. Thelepus nucleolata (Claparède, 1870) is described from the shallow Mediterranean and thus is sympatric with T. parapari. Thelepus hamatus is reported from Alaska to California (Moore 1906; Hartman 1969; Hilbig 2000) and is sympatric with T. cincinnatus at least in British Columbia: T. cincinnatus was reported from this province by Berkeley (1968) and it is the type locality of T. hamatus, despite not having been listed by Berkeley (1968).

\section{Acknowledgements}

The author thanks Prof. V. V. Malachov (Moscow State University) and Dr A. Sazhin (PP Shirshov Institute) for the use of equipment for preparing photographs. Mr D. 
J. Hall and Dr. T. M. Worsfold (APEM) for the loan of specimens and access to the APEM collection. Dr Marián Ramos, Principal Researcher of the "Fauna Ibérica XI" project and Dr Javier Sánchez Almazán, Collection Manager at the MNCN, for providing access and assistance in the study of the MNCN collection. Mr D. J. Hall and Dr T. M. Worsfold made edits to the English. Thanks also to The Centre for Environment, Fisheries and Aquaculture Science (Cefas), especially Mr Paul Mcllwaine, for providing material and data on T. davehalli. Dr. Christopher J. Glasby for his valuable and friendly comments on the manuscript and careful editing.

\section{Financial support}

This work was supported by the Russian Science Foundation (grant number 14-5000029) for studies in Russia and by Fauna Ibérica XI - Polychaeta VI" (Reference: MICINN CGL2010-22267-C07-01) outside of Russia.

\section{References}

Bellan G (2008) Thelepus cincinnatus. In: Read G, Fauchald K (Eds) (2017) World Polychaeta database. Accessed through: World Register of Marine Species at http://www.marinespecies.org/aphia.php?p=taxdetails\&id=131543 [Accessed on 2018-02-08]

Benham WB (1921) Polychaeta. Australian Antarctic Expedition 1911-1914, Scientific Reports, Series C - Zoology and Botany 6(3). William Applegate Gullick, government Printer, Sydney, 128 pp.

Berkeley C (1968) A checklist of Polychaeta recorded from British Columbia since 1923, with references to name changes, descriptions, and synonymies. II. Sedentaria. Canadian Journal of Zoology 46: 557-567. https://doi.org/10.1139/z68-073

Claparède E (1870) Les Annélides Chétopodes du Golfe De Naples. Genève et Bale H. Georg, Libraire, 10, Corraterie, Pt. 2, 225 pp.

Day JH (1955) The Polychaeta of South Africa. Part 3. Sedentary species from Cape shores and estuaries. Journal of the Linnean Society of London, Zoology 42(287): 407-452 http:// dx.doi.org/10.1111/j.1096-3642.1955.tb02216.x

Fabricius O (1780) Fauna Groenlandica, systematice sistens, Animalia Groenlandiae occidentalis hactenus indagata, quoad nomen specificum, triviale, vernaculumque synonyma auctorum plurium, descriptionem, locum, victum, generationem, mores, usum, capturamque singuli prout detegendi occasio fuit, maximaque parte secundum proprias observationes: Hafniae [Copenhagen] et Lipsiae., Polychaeta \& Annelida data, 266-315; 374-384. http://dx.doi.org/10.5962/bhl.title.13489

Fauchald K (1977) Polychaetes from intertidal areas in Panama, with a review of previous shallow-water records. Smithsonian Contributions to Zoology 221: 1-81. https://doi. org/10.5479/si.00810282.221 
Fauvel P (1927) Polychètes sédentaires. Addenda aux Errantes. Archiannélides, Myzostomaires. Faune de France 16: 1-404.

Grube AE (1878) Annulata Semperiana. Beiträge zur Kenntniss der Annelidenfauna der Philippinen. Memoires de L'Academie Imperiale des Sciences de St. Petersbourg, Ser. 7, 25(8): 1-300.

Hartman O (1959) Catalogue of the Polychaetous Annelids of the World. Parts 1 and 2. Allan Hancock Foundation Occasional Paper 23: 1-628.

Hartman O (1966) Polychaeta Myzostomidae and Sedentaria of Antarctica. Antarctic Research Series. Vol.7: 1-158. https://doi.org/10.1029/AR007

Hartman O (1969) Atlas of the sedentariate polychaetous annelids from California. Allan Hancock Foundation, University of Southern California, Los Angeles, 812 pp.

Hartmann-Schröder G (1996) Annelida, Borstenwürmer, Polychaeta. 2nd revised ed. The fauna of Germany and adjacent seas with their characteristics and ecology. Vol. 58. Gustav Fischer, Jena, Germany, 648 pp.

Hilbig B (2000) Family Terebellidae Malmgren, 1867. In: Blake JA., Hilbig B, Scott PV (Eds) Taxonomic Atlas of the Benthic Fauna of the Santa Maria Basin and Western Santa Barbara Channel. 7 - The Annelida Part 4. Polychaeta: Flabelligeridae to Sternaspidae. Santa Barbara Museum of Natural History 30: 231-293.

Hobson KD, Banse K (1981) Sedentariate and archiannelid polychaetes of British Columbia and Washington. Canadian Bulletin of Fisheries and Aquatic Sciences, 209, Ottawa, 144 pp.

Holthe T (1986) Polychaeta Terebellomorpha. Marine Invertebrates of Scandinavia 7, Norwegian University Press, 194 pp.

Hsueh P-W, Li K-R (2016) New species of Thelepodidae (Terebelliformia, Polychaeta) from Taiwan. Zootaxa 4170(3): 510-524 http://doi.org/10.11646/zootaxa.4170.3.5

Hutchings PA, Glasby CJ (1987) The Thelepinae (Terebellidae) from Australia, with a discussion of the generic and specific characters of the subfamily. Bulletin of the Biological Society of Washington 7: 217-250.

Imajima M, Hartman O (1964) The Polychaetous Annelids of Japan. Part II. Allan Hancock Foundation Publications Occasional Paper. University of Southern California Press Los Angeles, California. Vol 26: 239-452.

Jirkov IA (2001) [Polychaeta of the Arctic Ocean]. Yanus-K, Moskva, 632 pp. [in Russian] Jirkov IA, Leontovich MK (2013) Identification keys for Terebellomorpha (Polychaeta) of the Eastern Atlantic and the North Polar Basin. Invertebrate Zoology 10(2): 217-243.

Leuckart R (1849) Zur Kenntnis der Fauna von Island. Erster Beitrag (Würmer). Archiv für Naturgeschichte, Berlin. 15(1): 149-208, plate 3.

Londoño-Mesa MH (2009) Terebellidae (Polychaeta: Terebellida) from the Grand Caribbean region. Zootaxa 2320: 1-93.

McIntosh WC (1885) Report on the Annelida Polychaeta collected by H.M.S. Challenger during the years 1873-1876. Report on the Scientific Results of the Voyage of H.M.S. Challenger during the years 1872-76, Ser. Zoology 12: 1-554.

McIntosh WC (1922) A monograph of the British marine annelids. Polychaeta: Hermellidae to Sabellidae. London, Ray Society 4(1): 1-250. 
Moore JP (1906) New species of Ampharetidae and Terebellidae from the North Pacific. Proceedings of the Academy of Natural Sciences of Philadelphia 57: 846-860, plate XLVI.

Nogueira JMM, Hutchings PA, Fukuda MV (2010) Morphology of terebelliform polychaetes (Annelida: Polychaeta: Terebelliformia), with a focus on Terebellidae. Zootaxa 2460: 1-185.

Pettibone MH (1954) Marine polychaete worms from Point Barrow, Alaska, with additional records from the North Atlantic and North Pacific. Proceedings of the United States National Museum 103(3324): 203-356. https://doi.org/10.5479/si.00963801.103-3324.203

Read G, Fauchald K (Eds) (2018) World Polychaeta database. Terebellidae Johnston, 1846. Accessed through: World Register of Marine Species at: http://www.marinespecies.org/aphia. php?p=taxdetails\&id=982 [Accessed on 2018-03-01]

Roule L (1896) Annélides. Résultats scientifiques de la campagne du CAUDAN dans le Golfe de Gascogne. Annales de l'Université de Lyon 26: 439-471.

Schmarda LK (1861) Neue Wirbellose Thiere: Beobachted und Gesammelt auf einer Reise um die Erdr 1853 bis 1857. Turbellarien, Rotatorien und Anneliden. Leipzig, Verlag von Wilhelm Engelmann 1(2): 1-164.

Solís-Weiss V, Bertrand Y, Helléouet M-N, Pleijel F (2004) Types of polychaetous annelids at the Muséum national d'Histoire naturelle, Paris. Zoosystema 26(3): 377-384.

Treadwell AL (1901) The Polychaetous annelids of Porto Rico. Bulletin of the United States Fish Commission 20(2): 181-210.

Uschakov PV (1955) Monogoshchetinkovye chervi dal'nevostochnykh morei U.S.S.R. [Polychaeta of the Far Eastern Seas of the USSR]. Izdatel'stvo Akademii Nauk SSSR. Moscow \& Leningrad, 445 pp. [in Russian]

Zatsepin VI (1948) [Class Polychaeta]. In: Gayevskaja NS (Ed.) Identification keys for fauna and flora of the USSR northern seas Sovetskaya Nauka, 94-167. [in Russian] 